\title{
Online and blended entrepreneurship education: a systematic review of applied educational technologies
}

\author{
Li Chen $^{1}$ D Dirk Ifenthaler ${ }^{1,2}$. Jane Yin-Kim Yau ${ }^{1}$
}

Received: 13 January 2021 / Revised: 2 March 2021 / Accepted: 22 March 2021 / Published online: 16 April 2021 (C) The Author(s) 2021

\begin{abstract}
The supply and demand of entrepreneurship education at university level commenced in 1938. With the proven entrepreneurial effectiveness in economic development and the efforts of scholars, policymakers and other stakeholders, competencies in entrepreneurship are becoming a set of essential learning objectives. In the digital era, entrepreneurship education can be made available in an online and blended format. Thereby, this study presents a systematic analysis of research focusing on blended and online entrepreneurial learning and teaching. Based on five keywords, collating an initial set of 121 articles, this systematic review details the research outcomes of the resulting set of 38 published research articles/contributions, where each described a specific online and blended learning environment. We obtained and analyzed the following information from each of these articles: definition of entrepreneurship education, context of study, methodology, applied technology, focused group, sample, outcome of entrepreneurship education and research rigor. Our findings showed that the current research status and achievements scholars have contributed in educational technologies utilized by online and blended entrepreneurship education can be summarized into three categories: social media, serious games and Massive Open Online Courses. In order to compare these technologies, we selected five examples from three educational technologies and utilized a marking sheet for evaluation and assessment. In general, it was found that Wiki was used to discuss entrepreneurial concepts and that Facebook was the most common social software in entrepreneurship education. In terms of serious games, FLYGBY and SimVenture facilitated the gamification and enjoyment of entrepreneurship activities the most. Finally, as Massive Open Online Courses platform, Coursera offers plenty of/online entrepreneurship education courses. In a nutshell, in online and blended entrepreneurship education, social media was utilized to facilitate cooperation amongst participants; serious games were used to enhance students' enjoyment and engagement; and Massive Open Online Courses provided a platform as well as high-quality learning resources, anywhere anytime. Hence, each technology has advantages and challenges when we apply it to entrepreneurship education. We conclude that instructors
\end{abstract}

Extended author information available on the last page of the article 
and learners need to successfully compare and choose the most appropriate combination of technologies to achieve entrepreneurial course aims.

Keywords Entrepreneurship education · Blended and online learning · Social media $\cdot$ Serious games $\cdot$ Massive Open Online Courses

\section{Introduction}

The COVID-19 pandemic started in 2020 that has increased the speed in the facilitation of online and blended education, especially in higher education institutions, as the education of university students in developed countries has been moved online and will continue to be online until the pandemic is over. This created an obstacle for the provision of entrepreneurship education (EE) as it is a discipline, which requires students to acquire "learning by doing"-practical competencies and experiences in an authentic setting (Liguori \& Winkler, 2020; Kassean et al., 2015; Kuratko, 2005). However, due to the COVID-19, educators need to transfer offline educational activities into the online domain. To make this transition as seamless as possible and ensuring that the teaching and learning objectives are met, the emphasis was placed on the utilization of online and blended applications/technologies. Although there have been reviews on various technologies that have been applied in business education including a review of social media (Tess, 2013), a review of serious games (SGs) (Faria et al., 2009) in this context, as well as a general review of online and blended education (Arbaugh et al., 2009), there have been limited reviews conducted on the utilization and effectiveness of educational technologies in EE (Fayolle, 2013; Rashid, 2019). Various reviews of specific technology can be found; for example, Fox et al. (2018) built a criteria framework to review and evaluate serious entrepreneurial games; educational technologies applied to online and blended EE include technology-mediated to an intelligent method, e.g., computer aided instruction (CAI) (Petridou \& Sarri, 2011), information technology (Nisheva et al., 2009) virtual and augmented reality (Sousa, 2019; Tarabasz et al., 2018), and big data (Obschonka \& Audretsch, 2020). Our review of the articles which utilized technologies in EE encompasses the following: blog (Wagid \& Oliver, 2017; Udosen \& Upula, 2019), Wikis (Menkhoff \& Bengtsson, 2012), Facebook (Chang \& Lee, 2013; Ali et al., 2017), digital and non-digital serious games, course management system (Frederick, 2007; Wu et al., 2019) and MOOCs (Cirulli et al., 2016; Resei et al., 2018; Vorbach et al., 2019).

Our research is motivated by first the lack of a systematic review on how educational technologies have been effectively applied in EE and second the lack of information on the new technologies that have already been introduced to existing EE courses. One of the aims of this systematic review is to provide guidelines for informing decision-makers and educators about the advantages and challenges of the utilization of these technologies for $\mathrm{EE}$ and for supporting them in selecting appropriate tools for their courses. The reminder of the paper is divided into the following - a literature review is presented in "Literature review" section, our research 
methodology and questions are presented in "Research methodology" section, the results of our systematic review are presented in "Results of the systematic review" section, and thereafter a discussion and implications of this research in "Discussion" section followed by the conclusion in "Conclusion" section.

\section{Literature review}

A number of authors have presented research studies on entrepreneurship intention (such as Bae et al., 2014; Ngoc Khuong and Huu An 2016) and their implication (such as Henry et al. 2005; Oosterbeek et al. 2010); however, research studies on educational technologies in EE have been limited despite the practical development and presentation of online and blended EE courses using the internet and educational tools since the last twenty years. Currently, technologies such as Web 2.0, cloud computing and artificial intelligence have been utilized for supporting blended and online entrepreneurship teaching and learning. Student management and response systems (e.g., Moodle and Business Operation Support System) have been used to support learning and teaching as well as collect and analyze learning behavior data. Devices such as laptop or tablet computers, mobile devices and smartphones are used as a medium for teaching and learning entrepreneurial knowledge, skills and competencies. Many studies have been presented, which adopted different technologies in online and blended EE such as Web 2.0 (Jones \& Iredale, 2009), cloud computing (Holinska et al., 2019; Ratten, 2013), digital technology (Rippa, 2018), Massive Open Online Courses (MOOCs) (Al-atabi \& Deboer, 2014; Chang, 2017; Cirulli et al., 2016; Resei et al., 2018; Vorbach et al., 2019), social media (Ali et al., 2017; Chang \& Lee, 2013; Waghid, 2017) and Serious Games (SGs) (Protopsaltis et al., 2014; Romero \& Usart, 2013). The last three mentioned technologies have been broadly (in relative terms) adopted in online and blended EE. Educators typically adopt more than one technology for the implementation of their EE courses such as Facebook as the type of social media utilized on Moodle 2.0 as the learning management system. An EE course combining SGs within a learning platform has been presented by Protopsaltis et al. (2013) and one combining SGs with social media has been presented by Wu and Song (2019). In order to compare different combinations of technologies deployed in EE courses, a definition of EE needs to be specified, which is detailed in the next section.

\section{Entrepreneurship education}

EE is rarely defined or conceptualized (Fayolle, 2013). Based on the definitions from Sexton and Bowman (1984), Gibb (2002), Rasmussen and Sørheim (2006) and Liñán (2004), EE consists of learning activities, which allow learners to acquire entrepreneurial knowledge, skills and attitudes necessary for creating and operating a business. The Global Entrepreneurship Index Report 2018 (relating to the entrepreneurship ecosystem) highlighted that the Global Entrepreneurship Index scores have increased by $3 \%$ worldwide (Acs et al., 2018). It showed that North American 
and European account for 15 occupations in the top 20. The performance of EE presented a similar distribution. Commonly, EE originated from the USA and become a mainstream discipline in business schools as well as other schools in higher education institutes (HEIs), partly because innovation is the most consequential characteristic in American culture, education and society, which meets the requirements of EE (Brooks et al., 2019). Due to various existing welfare systems and cultures, entrepreneurship and EE in Europelag behind those of the USA (Potter et al., 2008; Karimi \& Chizari, 2010). Therefore, European policy decision-makers executed many initiatives to chase the trend. The implementation of the Bologna Process (Keeling, 2006) facilitated European universities and colleges to be more innovative and entrepreneurial (Potter et al., 2008). The European Commission built an entrepreneurship competence framework containing three competence areas and 15 specific competencies to guide entrepreneurial academics and actions (Bacigalupo et al., 2016). Australia ranked first in the Asia-pacific area in the 2018 report and offered 584 entrepreneurship subjects in 2015 (Maritz et al., 2015). 70\% of Malaysian HEIs have built entrepreneurship incubators, and they offered entrepreneurship activities in almost every university (Cheng et al., 2009; Rahim et al., 2015). Chinese Ministry of Education takes the entrepreneurial course as a general and compulsory course in higher education institutes.

EE plays an important role at different stages of education; however, current EE courses as well as researches are typically available and popular in HEIs (or business and management schools) as under-, post-graduate degrees or MBAs. Many researchers attempt to answer "Why," "How," "What," "Who," "When," (von Graevenitz et al., 2010; Lackéus \& Middleton, 2015) and "Where" questions related EE (Karimi \& Chizari, 2010; Zhou \& Xu, 2012). A number of empirical studies of EE have been conducted including Fox et al. (2018) and Wu et al. (2018) as well as meta-analyses conducted by Martin et al. (2013), Schlaegel and Koenig (2014), and Bae et al. (2014). These studies were conducted from a variety of disciplines such as business, education, engineering and computer science.

\section{Educational technologies deployed in EE}

"Educational technology is the study and ethical practice of facilitating learning and improving performance by creating, using and managing appropriate technological processes and resources" (Januszewski \& Molenda, 2013). As the routine of pedagogy of EE is from teacher-led to student-centered (Robinson et al., 2016) and constructivism (Löbler, 2006), the tendency of educational technologies changes from teaching design to learning environments (Januszewski \& Molenda, 2013). Namely, the key objective of entrepreneurial educational technologies is to facilitate active, intentional, constructive and collaborative learning.

Many different but similar concepts of learning environments were utilized; for example, Moore et al. (2010) argued that the analysis of various ingredients of learning environment was essential. According to the percentage of technologies used in education, 30-79\% consisted of blended courses and $80+\%$ consisted of online ones (Allen \& Seaman, 2008). Siemens and Tittenberger (2009) noted that EE utilized 
additionally augmented technology extending the classroom, blended and online learning approaches. Watson (2008) argued that blended learning was a connection between F2F (face-to-face) and fully online learning. Online learning is considered as the utilization of the Internet and a computer to deliver courses. Therefore, the definitions of learning environments have not been unanimously endorsed. When a definition of online and blended learning was required for the application of EE courses, researchers tended to adopt their self-definition in their research (namely descriptive definition). Bonk and Graham (2004) argued that blended (hybrid) learning was a combination of F2F learning and distributed learning, which is centered on computer or mobile technologies. Course designers adopt both online and offline activities in a real or virtual classroom through using synchronous and asynchronous educational technologies (Frederick, 2007).

Compared with F2F EE courses, educational technologies are indispensable when students participate in entrepreneurship activities in online and blended entrepreneurial learning environments. Besides, educational technologies bring with the trend that online and blended entrepreneurial courses are becoming one of the main choices for students, educators and enterprises. Furthermore, a large number of applications applied to EE are produced and updated (e.g., Second Life, Facebook and online forums), because developers customize certain education technology to meet the needs of stakeholders, while studies of entrepreneurial educational technologies are scattered and systematic reviews on this topic are lacking. Due to time and resource constraints, developers of educational technology focus on one or two technologies, develop and experiment with one system or application (Buzady \& Almeida, 2019). Researchers do not tend to compare the effectiveness of two or three technologies. Besides, educators and learners need to understand the advantages and challenges of technologies, which is a basis for choosing a suitable one for learning and teaching. Therefore, conducting a systematic review and comparing the educational technologies utilized in EE are essential for combining theory and practice to construct a successful EE course.

\section{The difference of entrepreneurship teaching and learning}

Entrepreneurship pedagogy, the effectiveness for sociality and the economy are the main objectiveness for EE (Fayolle, 2008). Concerning entrepreneurship pedagogy, namely entrepreneurship teaching and learning, the two concepts are defined for it to be understood clearly. Here, we analyzed both from the objective, research, method and evaluation aspects. EE is not directly aimed at increasing the number of startups and entrepreneurs, but enhancing the life-long skills that a graduate needs for undertaking business endeavors or finding an occupation in the future (Jones, 2010). Clearly, entrepreneurship teaching aims to deliver entrepreneurship knowledge, convey entrepreneurship skills and teach students how to start a business (Gibb, 2002). As entrepreneurship learning relates to individuals and their backgrounds, there is a gap between teachers' teaching and learners' learning. Teacher's self-learning and reflection processes affect entrepreneurship teaching (Seikkula-Leino et al., 2010), while factors from the learners'/learning side are more sophisticated, such as their 
age (Honjo, 2004), education (Barringer et al., 2005), family entrepreneurs (Wadhwa \& Aggarwal, 2009) and personality traits (Barkham, 1994).

There are several traditional and non-traditional methods related to EE: lectures, guest speaker, action-based entrepreneurship programs (esp. workshop, study visits, counselling, setting up a business, games and practical training) (Hytti \& O’Gorman, 2004; Rasmussen \& Sørheim, 2006). In theory, every method is equal to be introduced into the entrepreneurship class. In practice, learner's preferences and experiences affect learning method choice. As one assumption said: "students will encounter a similar set of circumstances in the future for which they will be better prepared" (Fiet, 2001), instructors' teaching design applied simplified and generalized entrepreneurship process. However, the authentic entrepreneurship learning environment is vague and complicated, since learners learn from daily life as well. Entrepreneurship learning is the core aim to evaluate EE in all learning levels. The top five variances measured in entrepreneurship programs: perceptions, attitude, self-efficacy, entrepreneurial orientation and creativity that are related to learners. And studies of "training" only occupied 7\% (Huang-Saad et al., 2018). That means the number of qualified and trained teachers, the number of courses and programs, and teacher activities (Vesper and Gartner, 1997; Purzer \& Fila, 2016) are less mentioned. In the end, entrepreneurship teaching and learning are different when adopting educational technologies, which we discuss in the "results" and "discussion" sections. To advance the effectiveness and efficiency of EE, basing on the studentcentered concept, our scholars, policy-decision makers and stakeholders need to focus on entrepreneurship learning.

\section{Research methodology}

\section{Research questions}

We conducted a systematic review and compared the utilized technologies from three aspects-pedagogy, usability and technological. Five concrete examples have been selected for analysis and comparison in detail. The research questions are:

1. How are SGs, social media and digital platforms (mainly MOOCs) technologies applied in online and blended EE?

2. What are the strengths and weaknesses of SGs, social media and digital platforms (mainly MOOCs) in online and blended EE?

\section{Methodology}

The main research objective was to conduct a systematic review, based on Okoli's (2015) eight steps, of the application of educational technologies in online and blended EE. The articles under review were limited to the last twenty years (2000-2020) and in the English language. The focus was on "educational 
technologies" with "entrepreneurial education" and not "technology entrepreneurship", "university incubator" and "technology transfer". The utilized keywords included "entrepreneur* education," "education technology*," "blended," and "online". We searched journals of high impact factor in EE such as Journal of Business venturing, The Piccola Impresa/Small Business Journal, Education + Training, Technovation, International Small Business Journal: Researching Entrepreneurship, Academy of Management Learning and Education, Entrepreneurship Theory and Practice, Journal of Small Business Management and International Entrepreneurship and Management Journal (Fig. 1).

We also searched Google Scholar, Web of Science and ScienceDirect as well as 7 MOOCs platforms to collect the description of EE courses. Focusing on technologies in EE such as "distance learning," "blended learning," "online learning," "e-learning," and "mobile learning" as well as relevant technologies such as "Web 2.0," "Wiki,"

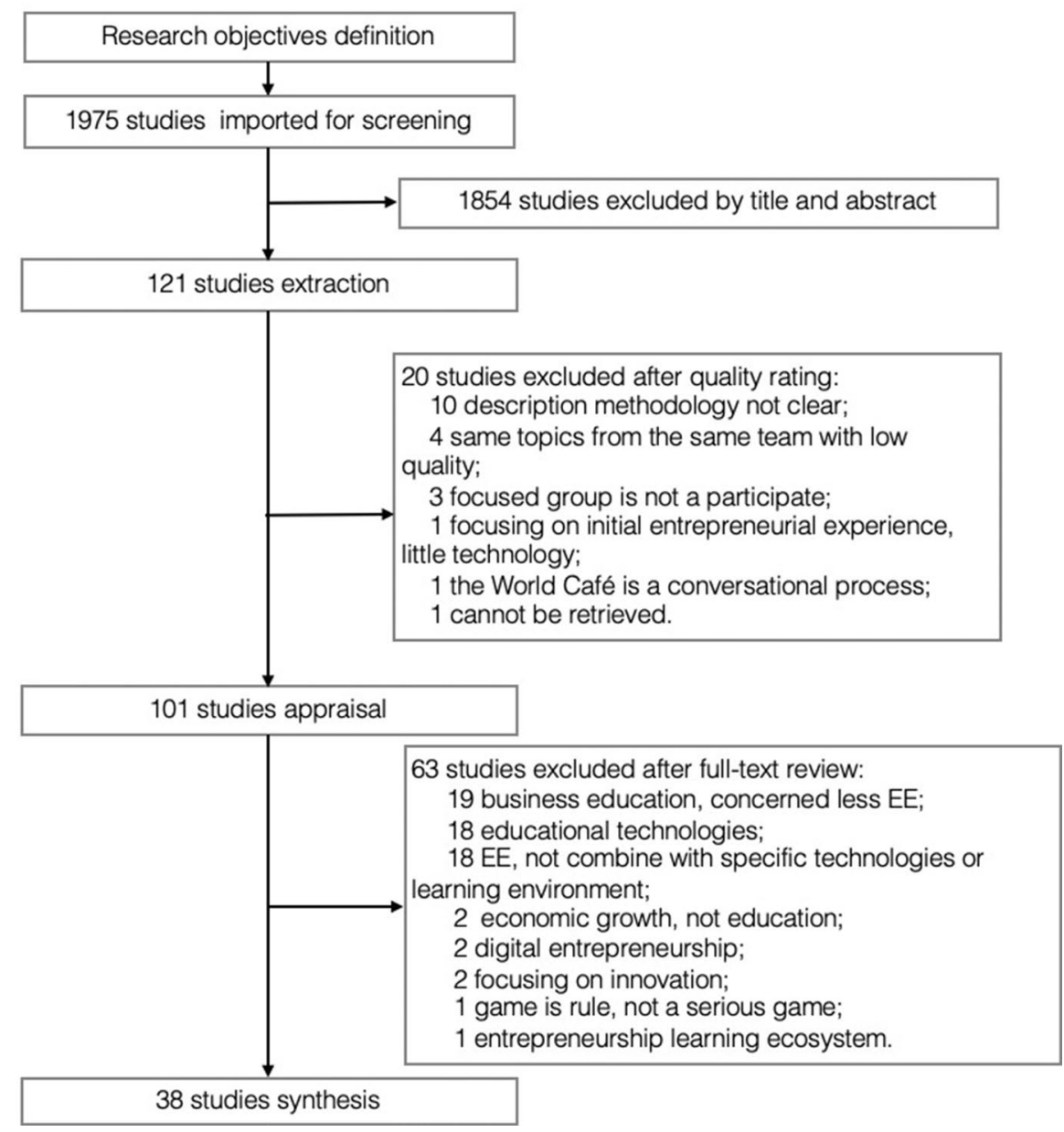

Fig. 1 Steps of literature collection 
"Information and communication technology (ICT)," "MOOCs," "social media," and "SGs". The string search combination showed another 121 articles between 2006 and 2020. 61 of the 121 studies were excluded after full-text review due to irrelevance. We conducted a quality appraisal step based on checklists of analyzing research quality (O’Brien et al., 2014; Tong et al., 2007; Mager \& Nowak, 2012) with the following quality criterion: the description and appropriateness of clear research questions, sampling selection, data collection, data analysis and synthesis. The end result was 38 high-quality studies to be analyzed in our systematic review and classified into three categories: Social media, SGs and digital platforms (mainly MOOCs).

\section{Results of the systematic review}

The collected 38 articles were divided into specific adopted technologies: social media (9), SGs (20) and MOOCs (9) are listed in Table 1. Every study was scrutinized from the definition of entrepreneurship education, the background of the study, methodology, applied technology, focused group, sample, the outcome of entrepreneurship education and research rigor. The literature was cited 25 times $(\mathrm{SD}=28, \mathrm{Min}=1, \mathrm{Max}=133)$ on average. The studies are scattered in Italy (5), USA (4), Taiwan, China (4), Malaysia (4), UK (4), Germany (2), Greece (2), Spain (2), Austria (2), Holland (1), Hungary (1), Switzerland (1), Romania (1), South Africa (1), Portugal (1), Ireland (1), Indonesia (1) and Russia (1). Research rigor was measured from the rigor of theory background, method, result, discussion and conclusion. In terms of research rigor, we rated the articles as strong (3), moderate + (7), moderate - (20) and weak (8) levels.

A variety of digital technologies in the online and blended environment have been adopted into EE such as cloud computing (Holinska et al., 2019), learning analytics (Toledo et al., 2020), there digital (3D) virtual reality, SGs (Lameras et al., 2015), social media, digital platforms, big data (Secundo et al., 2020; Sousa, 2019) and so on. The emphasis of these works has been on the implementation, and lack of appropriate or relevant research on the pedagogical and usability aspects. The results of our systematic review showed that the first study on online and blended EE was conducted in 2006 (Arbaugh et al., 2010). Commencing from 2010, entrepreneurial courses have been made available on MOOCs platforms in cooperation with different universities and there have been a number of SGs developed by the games industry to enhance EE. Before the pandemic, learners may have still preferred the F2F format compared with the online and blended version, despite the increased popularity in the latter. However, during the pandemic where the availability of courses were only limited to online, there has been an increased interest in the online and blended EE courses.

\section{Social media in EE}

Social media is a method of Web 2.0 that places emphasizes on the exchange of views with other learners (Jones \& Iredale, 2009). A majority of the new generation born in the digital era embrace social networking sites (SNS) and often fill their daily lives with communicating with others via social software, which is perceived 


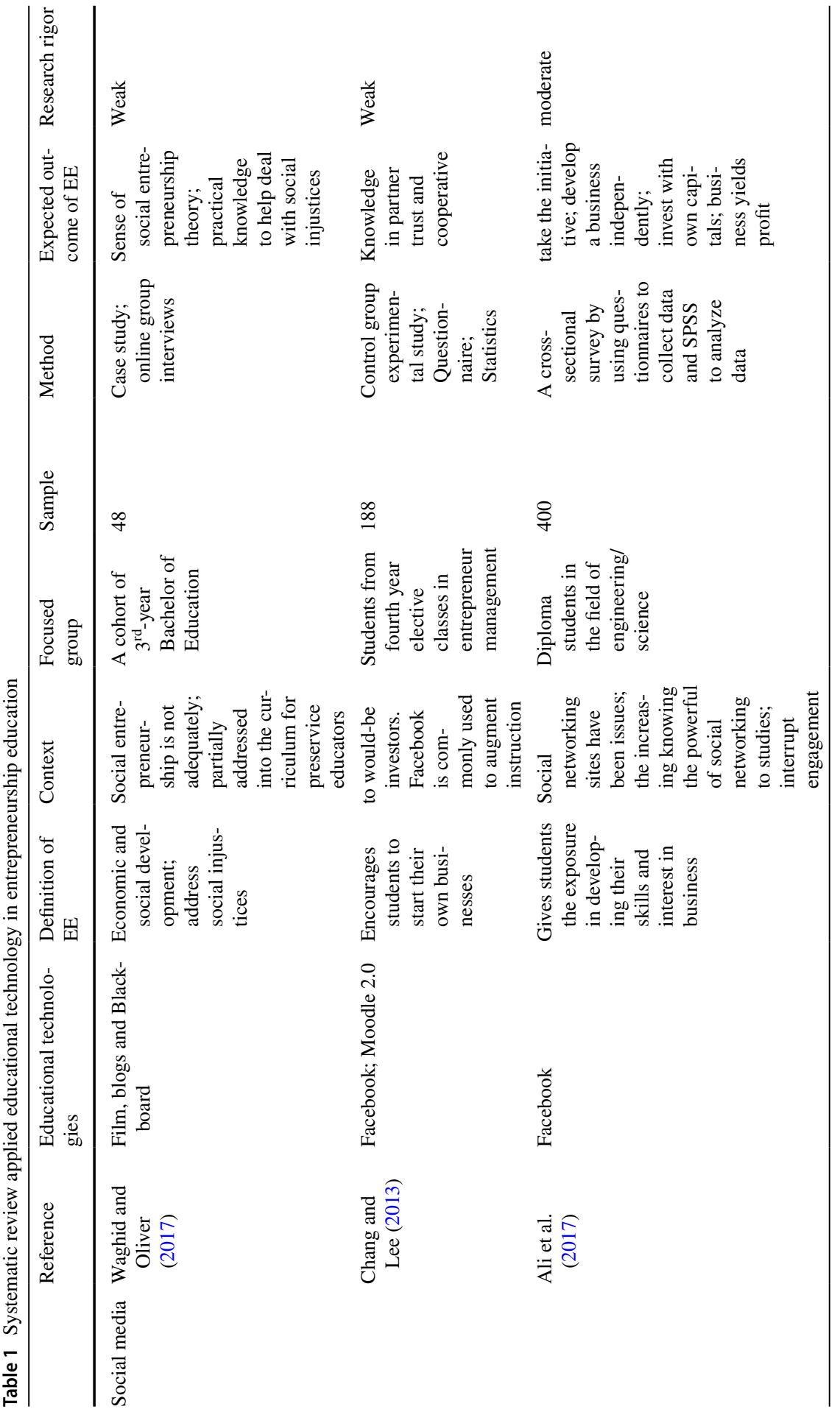




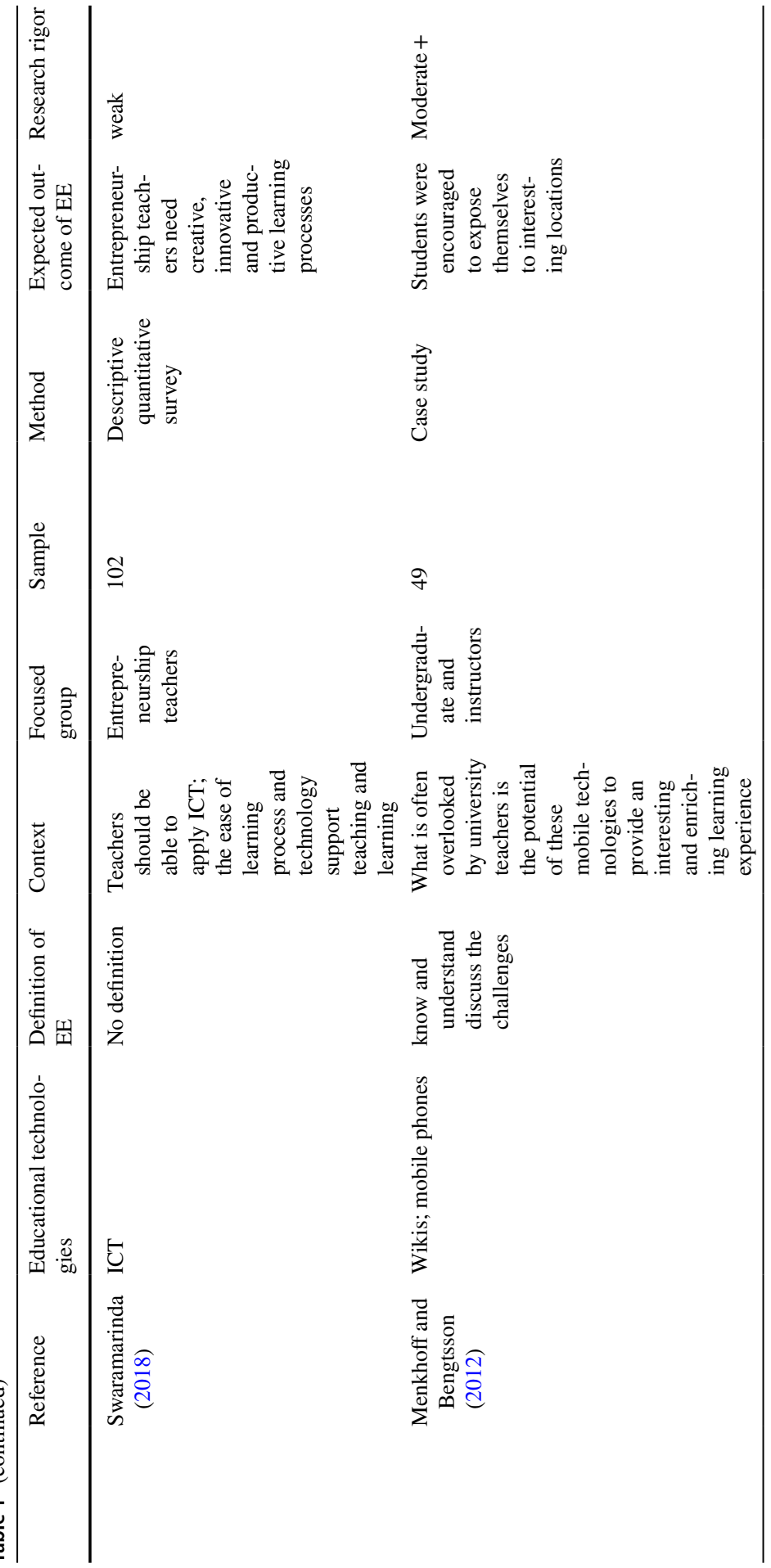




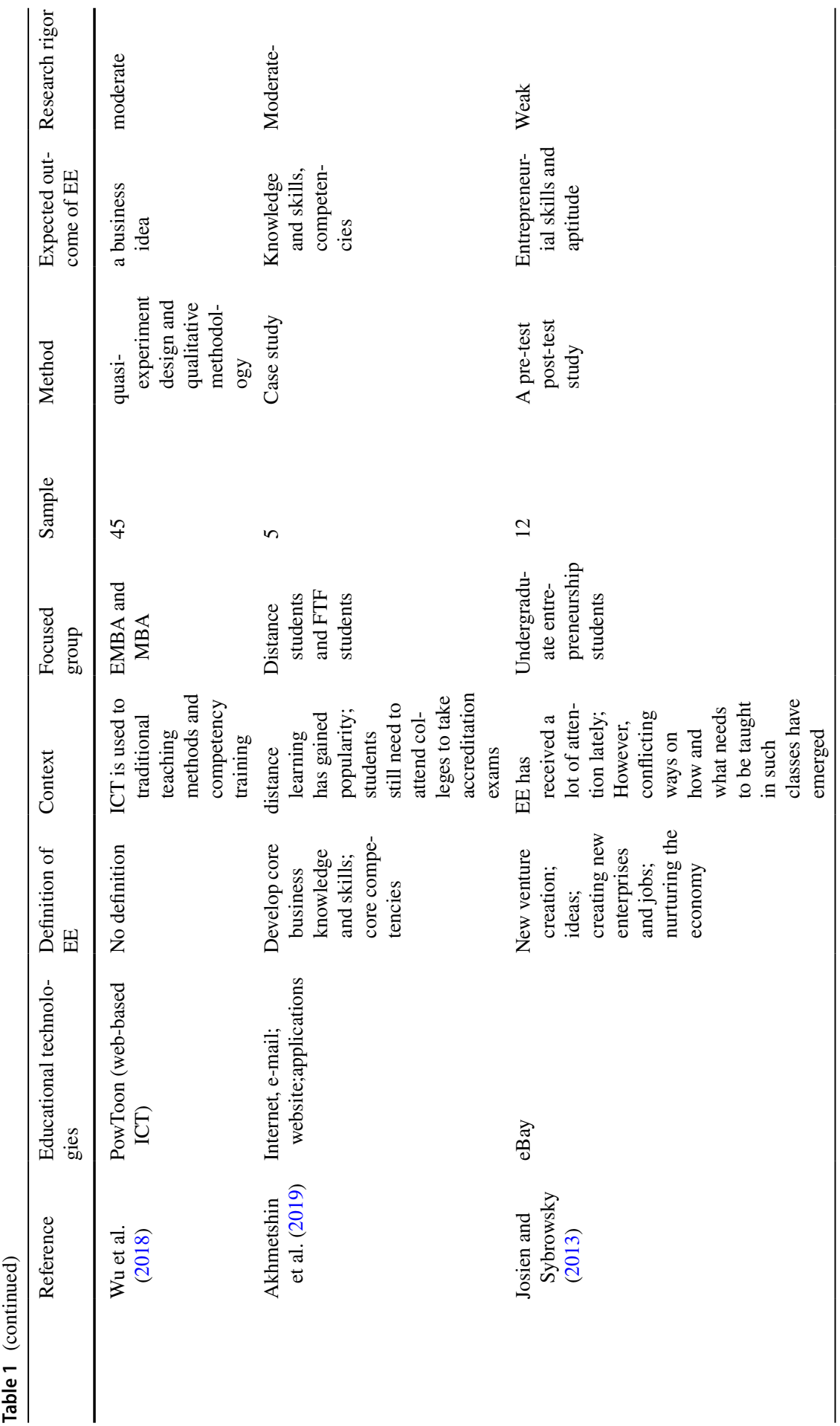




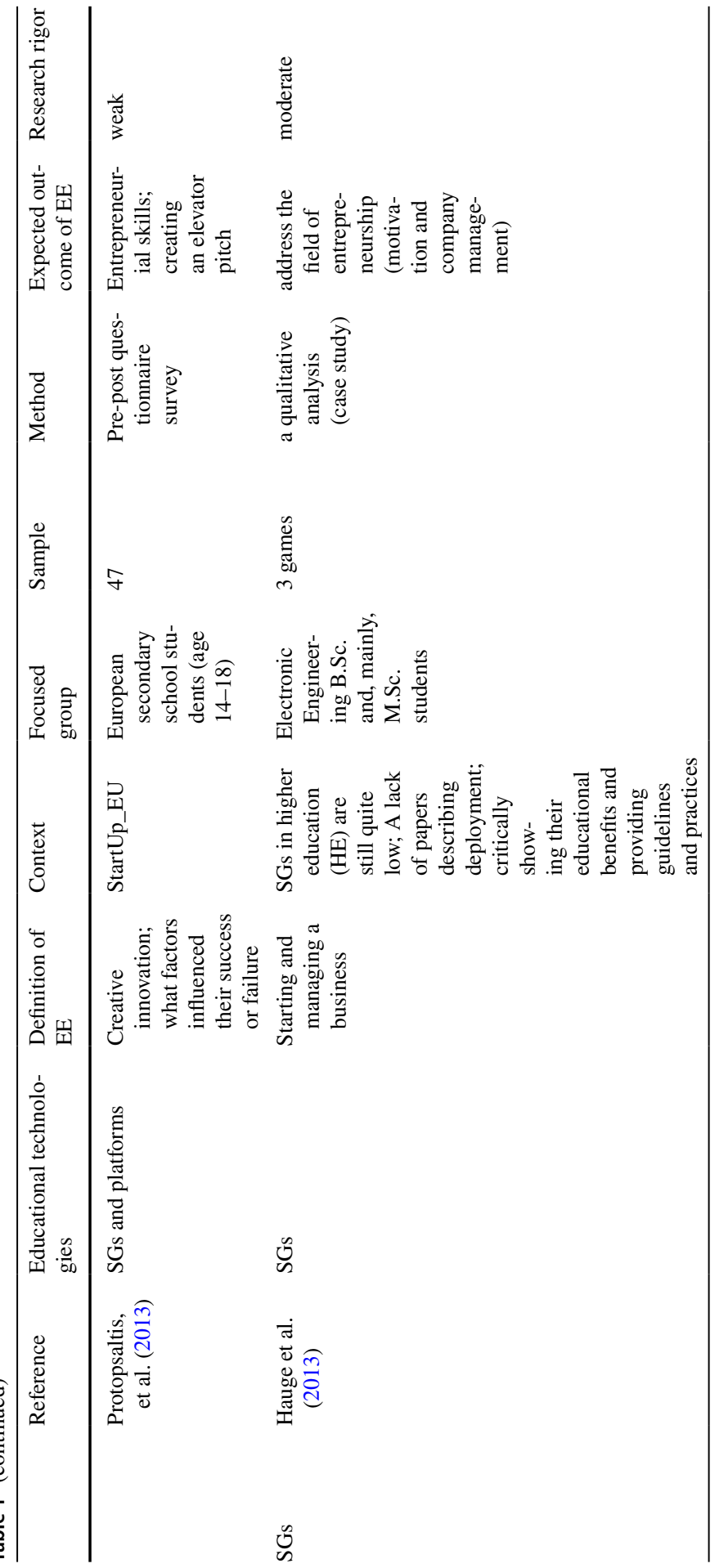




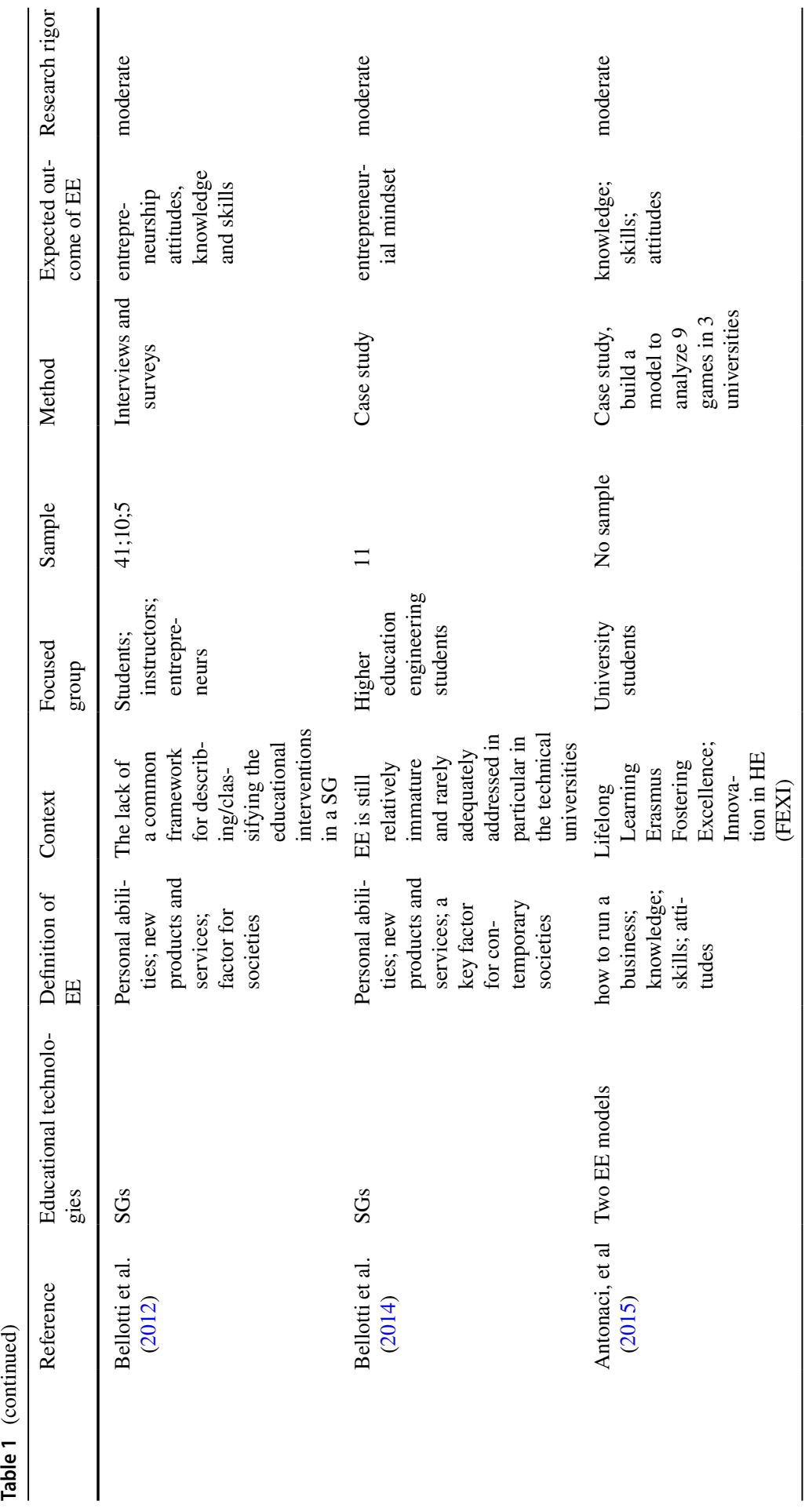




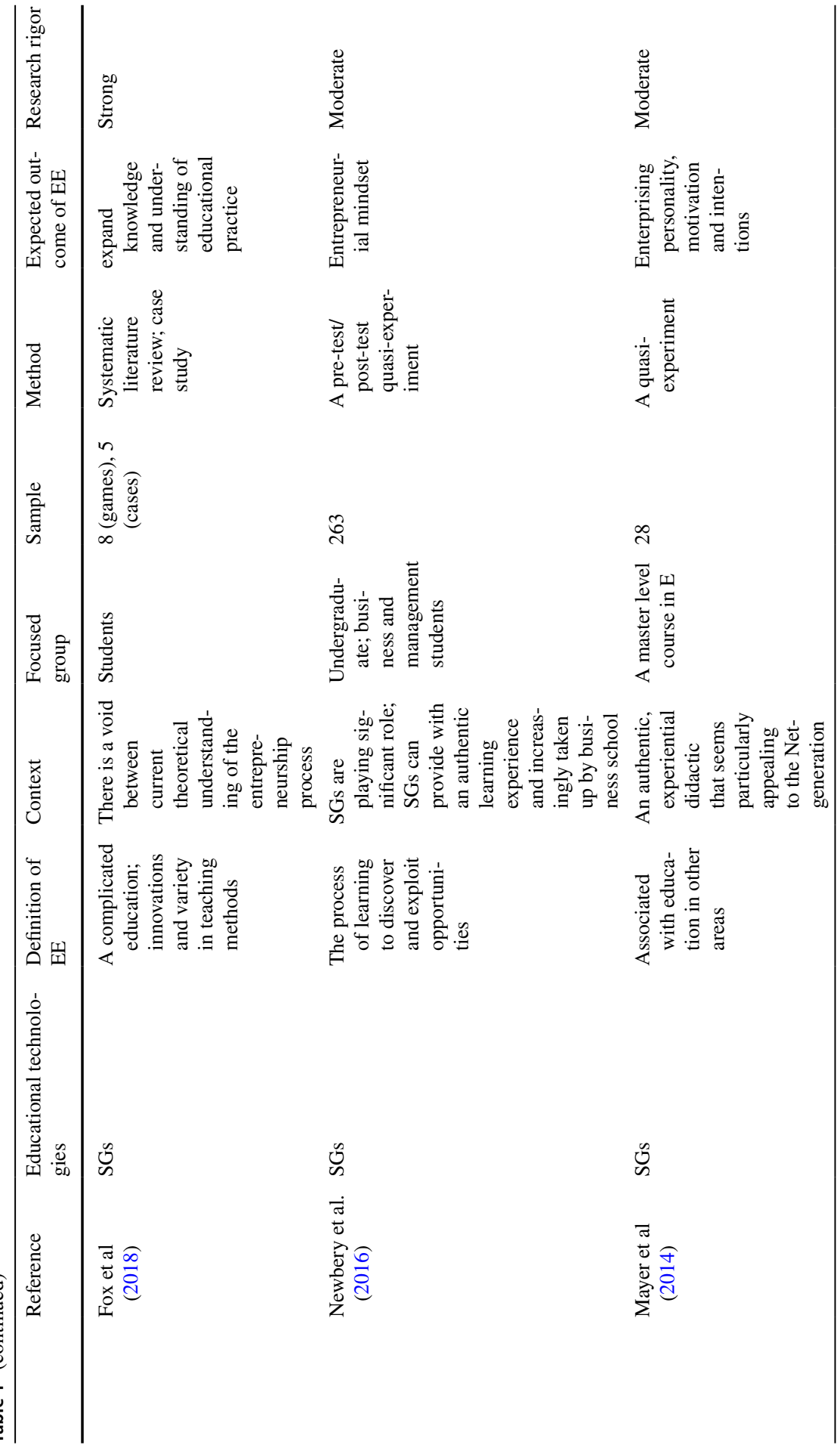




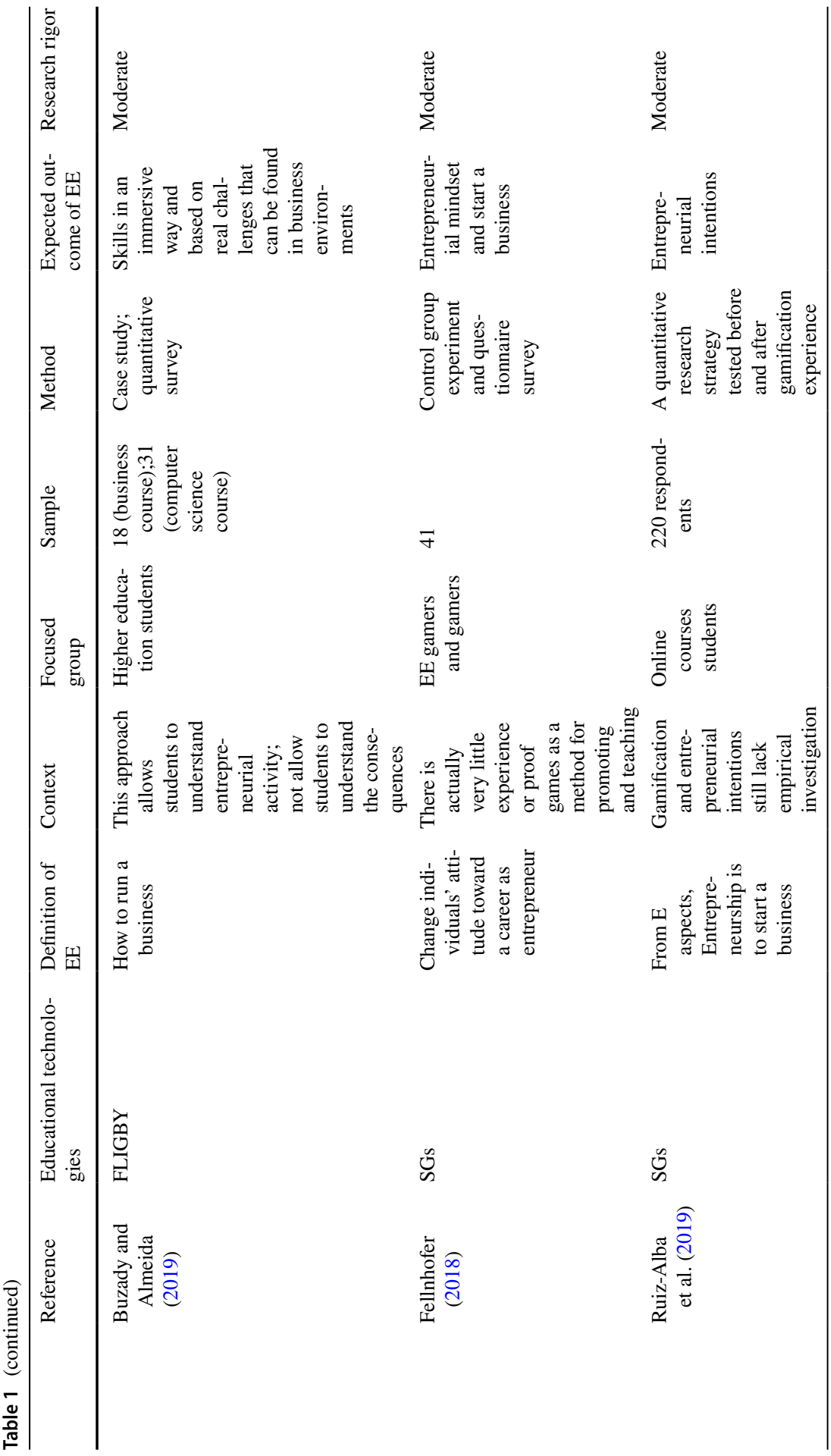




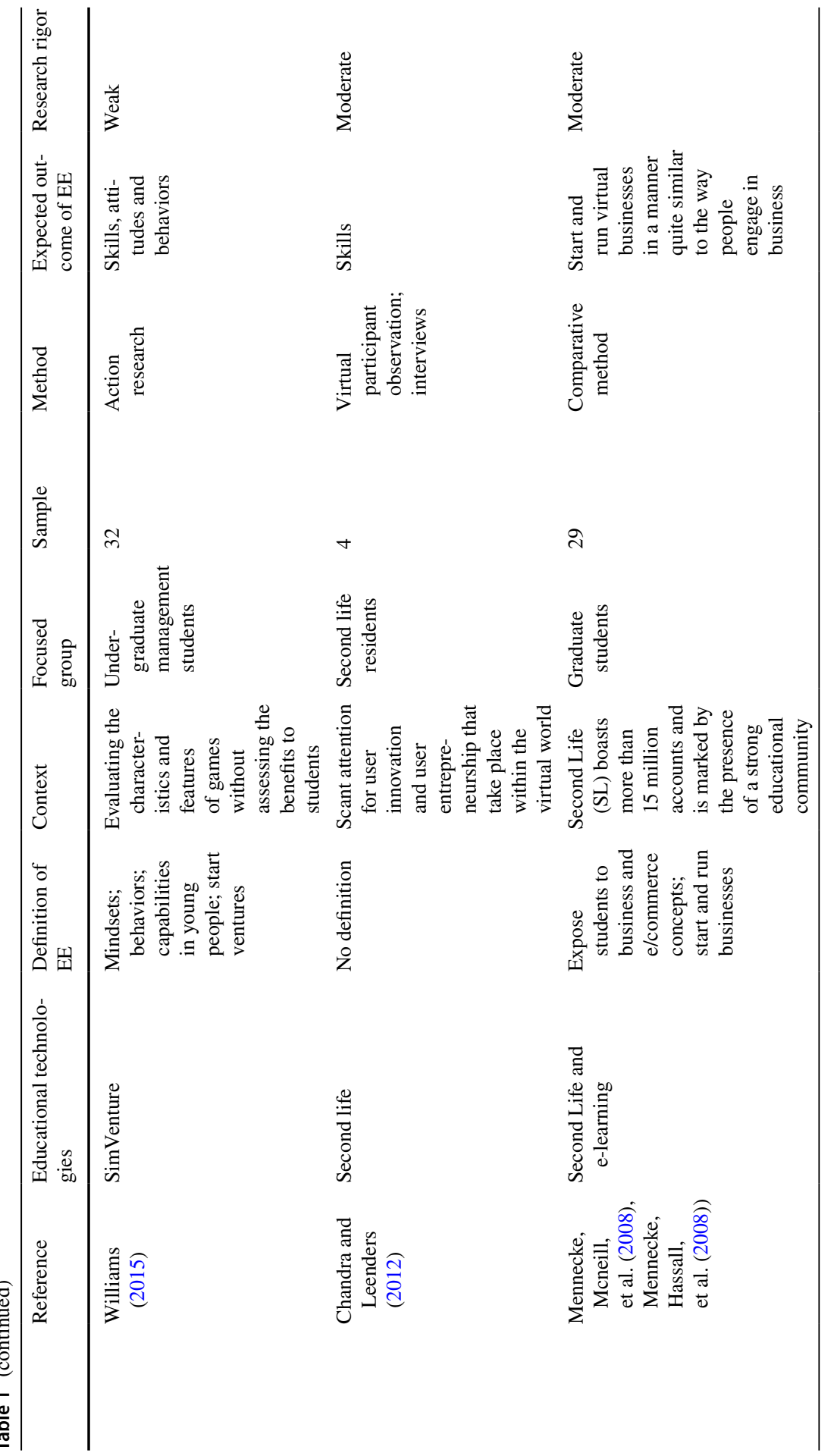




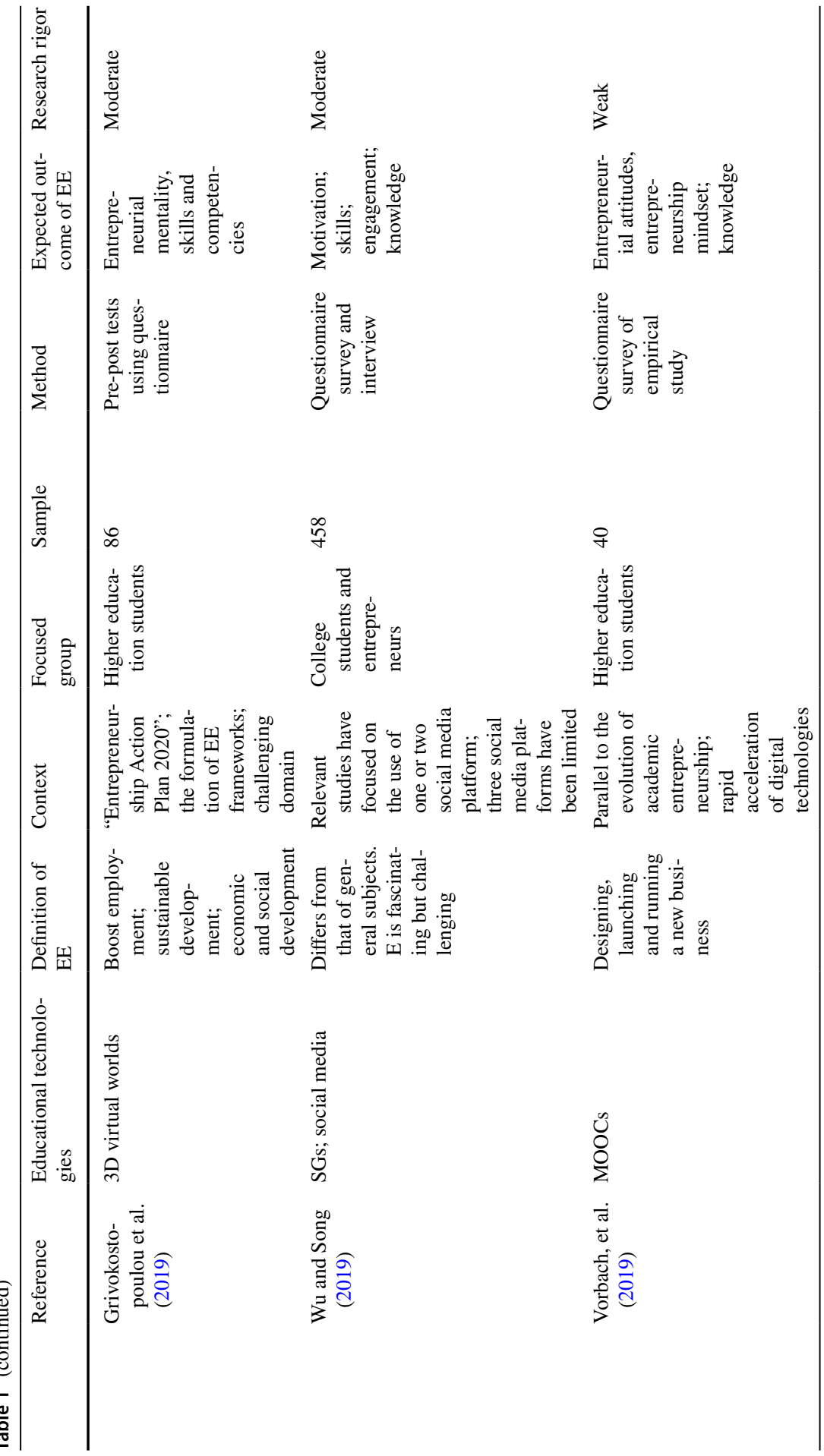




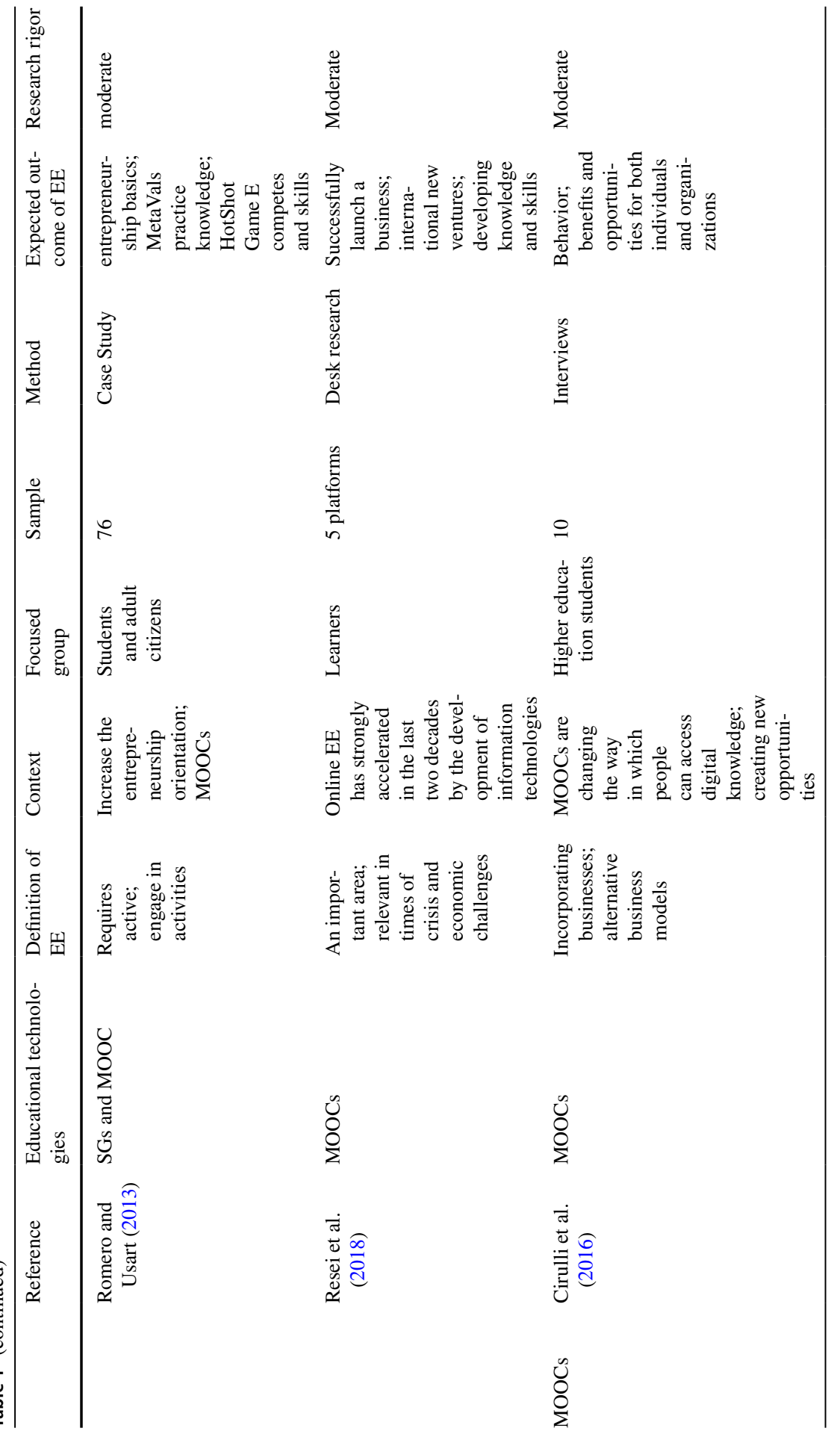




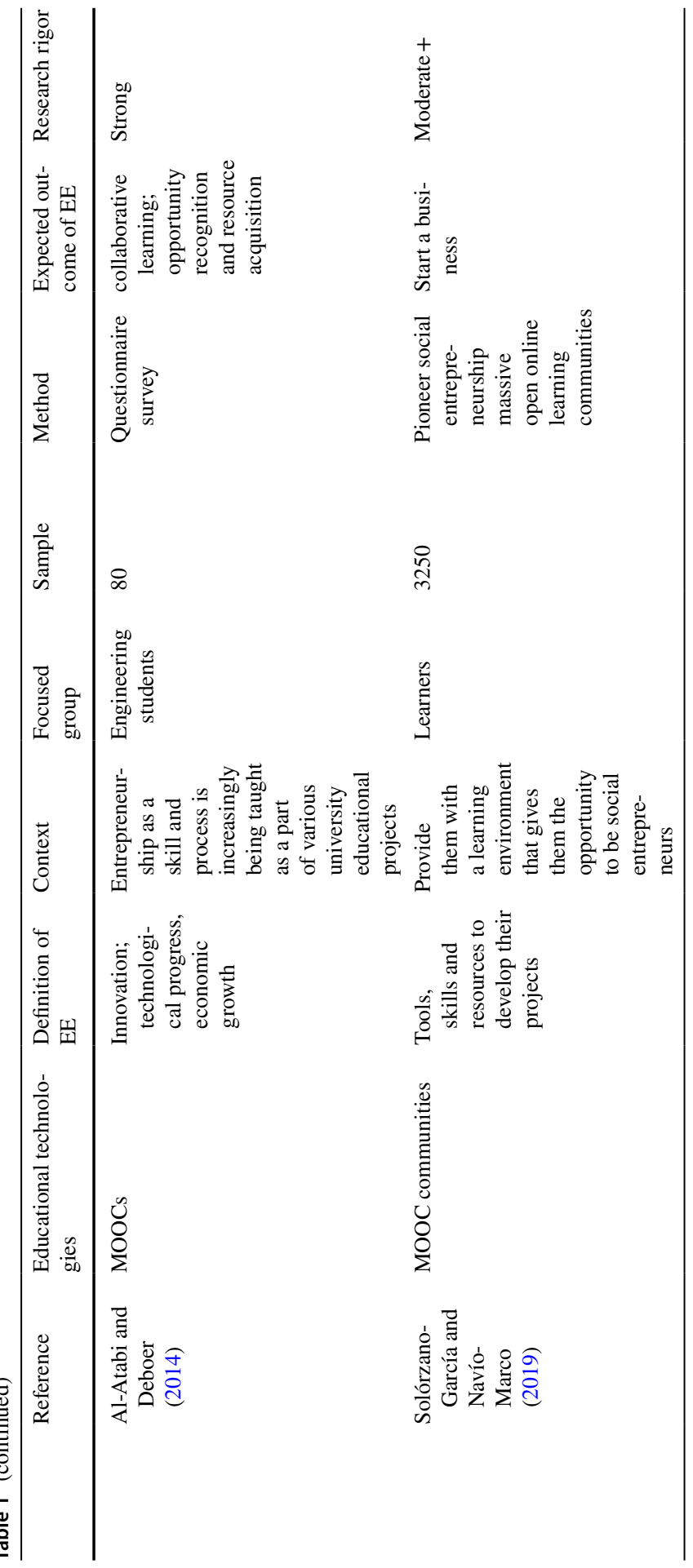




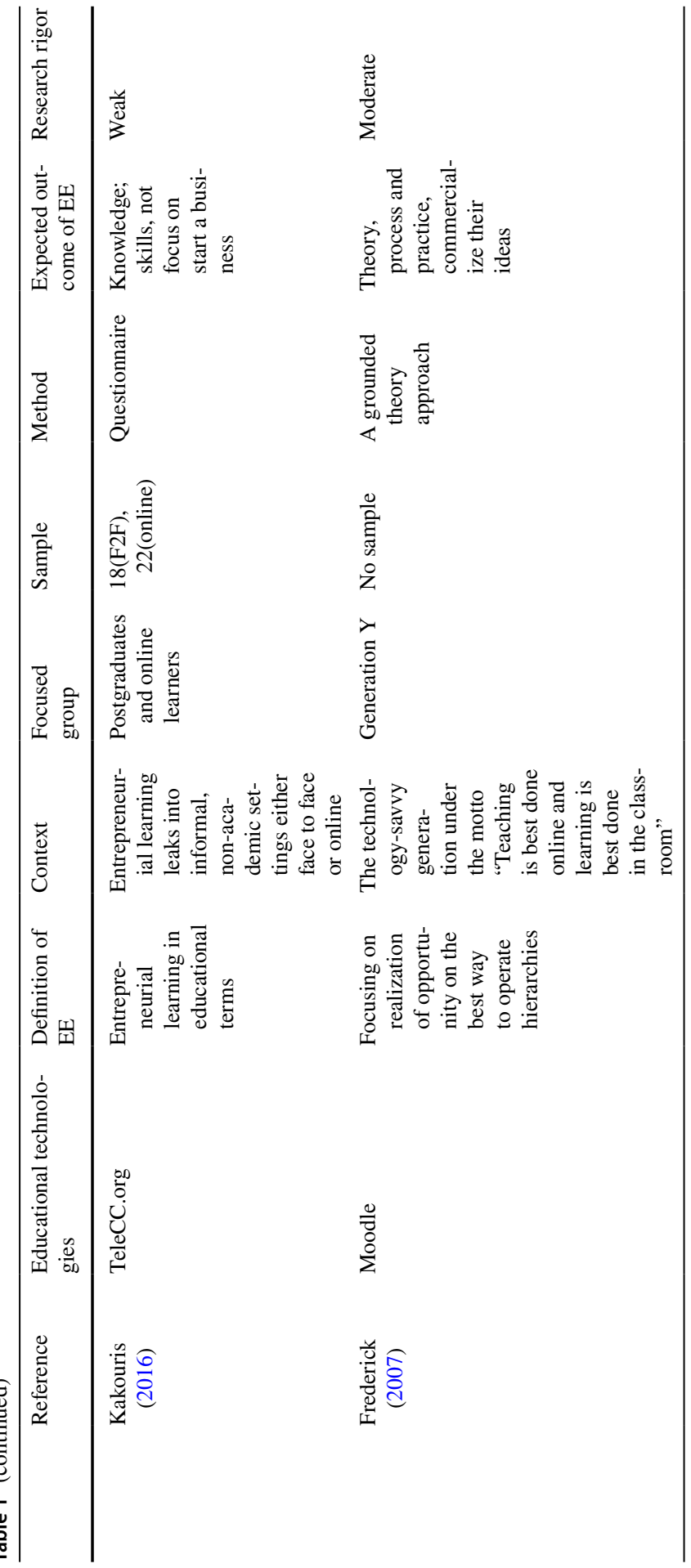




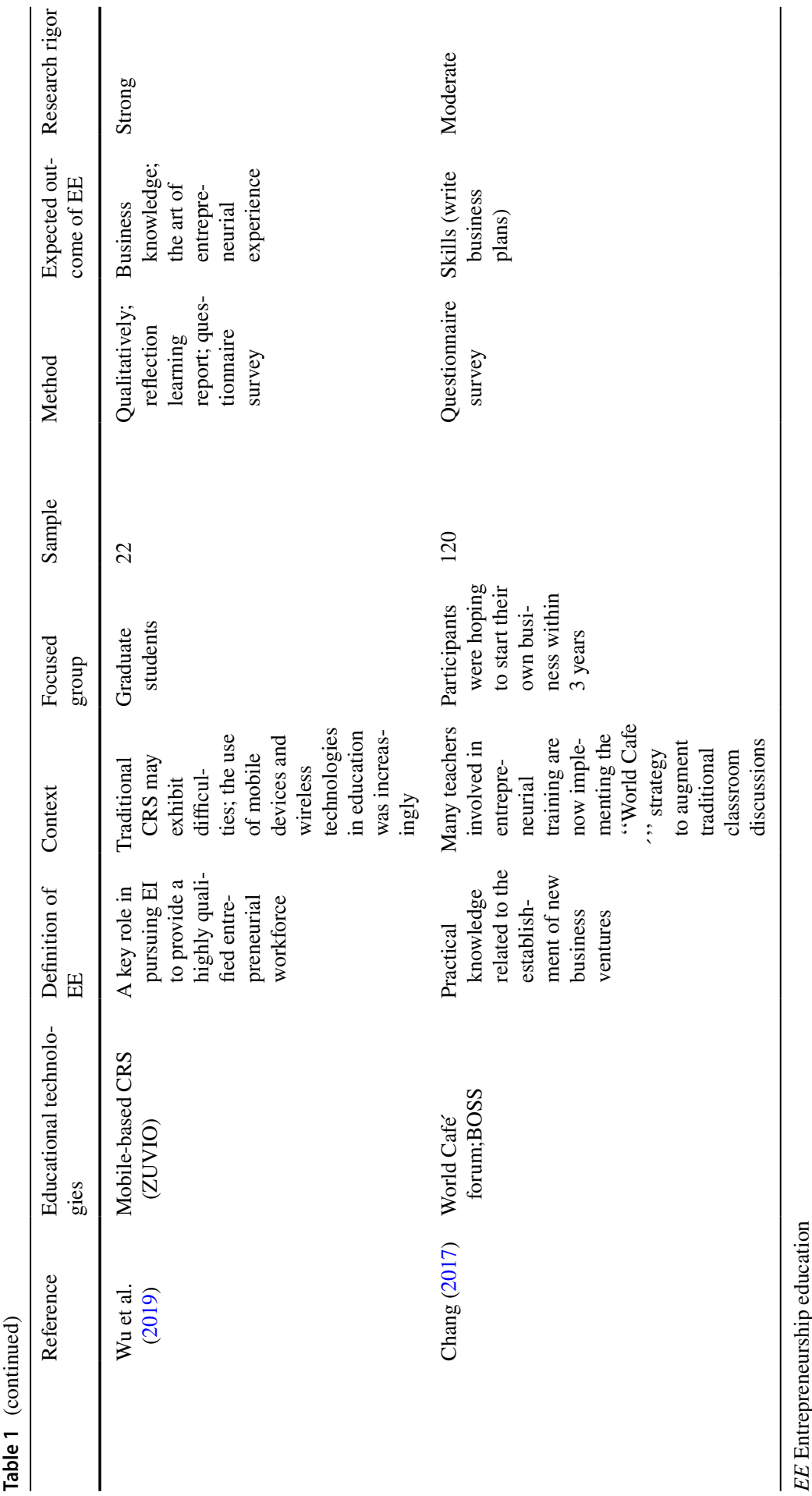


as a welcome way of building distributed human interaction. Additionally, college students adopt social media to informal and formal learning (Dabbagh \& Kitsantas, 2012), increasing student engagement (Blaschke, 2014) and satisfaction (Barczyk \& Duncan, 2012). Most importantly for entrepreneurship learners, one aim of taking an EE course is to build a social network and human relations (Man et al., 2002; Mitchelmore \& Rowley, 2013), where participants communicate with each other (e.g., Facebook, Twitter and WhatsApp) and show their life (e.g., Snap Chat, YouTube and Instagram) and work experiences (e.g., LinkedIn, Facebook and ResearchGate) in social media sites and applications. Kaplan and Haenlein (2010) classified social media into two branches: social presence and media richness and self-presentation and self-disclosure. Self-presentation (e.g., personal profiles) is the impressions that other users form on the user. It is one basic function of social media and has a connection with conversation and relationship (Kietzmann et al., 2011). Since this study specially analyzed SGs which overlaps with the taxonomy of Kaplan and Haenlein (2010), we excluded them in this section and classified papers $(n=9)$ using social media technologies into four sub-areas: the extent of media richness (namely, low and high) and interaction level (namely, weak and strong), which is shown in Table 2.

When designing a course, an animated business plan presentation tends to give better and more attractive results than a presentation without animated videos $(\mathrm{Wu}$ et al., 2018). Video reflection is a supplement teaching tool for written reflection (Wraae et al., 2020). Based on the benefits of different social media applications, educators introduced text-based, audio-based and/or video-based versions into students' learning processes. It is noted that schools were ready to utilize information communication technologies, whereas teachers themselves still lack the readiness (Swaramarinda, 2018). In EE, social networking sites are supplementary technologies for interaction and communication, More specifically, bachelor students using a wiki (namely, Wetpaint) to create and edit e-commerce websites together through brainstorm (Barczyk \& Duncan, 2012). Learners can communicate with other learners, entrepreneurs and entrepreneurship consultants in the Facebook and the Facebook community when attending a business planning course (Chang \& Lee, 2013). YouTube is used to post presentation videos in business education (Alon \& Herath, 2014). Online students record and upload an elevator pitch video to YouTube in entrepreneurial management open by Royal Roads University. The website of eBay also works as an experimental learning tool. Students upload their information of goods and consumers bid on the website (Josien \& Sybrowsky, 2013).

Table 2 Classification of social media in entrepreneurship education by media richness and interaction

\begin{tabular}{llll}
\hline & \multicolumn{1}{l}{ Media richness } & \\
\cline { 2 - 4 } & Low & High \\
\hline Interaction & weak & $\begin{array}{c}\text { Collaborative projects (e.g., } \\
\text { Wikis, podcast and blog) }\end{array}$ & Content communities (e.g., YouTube and eBay) \\
& strong & Forums (e.g., Moodle forums) & $\begin{array}{c}\text { Social networking sites and applications (e.g., } \\
\text { Facebook, Skype, WhatsApp and Twitter) }\end{array}$ \\
\hline
\end{tabular}


In Internationalization of Entrepreneurial Marketing Education courses, students located in three different countries often met and conducted many of their teamwork activities in a virtual environment through the utilization of Skype, WhatsApp and other social media tools (Reid et al., 2018). The Chinese Entrepreneurial and Asian Business Networks course is taught in a Singapore university where learners utilized Mediawiki and SNS to send messages to each other on their mobile devices (Menkhoff \& Bengtsson, 2012).

SNS promotes sharing learning materials and resources, like sharing photos on the Flickr site (Menkhoff \& Bengtsson, 2012). Also, personalized content service is provided by utilizing social media that facilitates self-regulated learning (McLoughlin \& Lee, 2010). Besides, social media usually combine with digital educational platforms (Chang \& Lee, 2013; Waghid, 2017), augmented reality (Gupta \& Bharadwaj, 2013), or work as a technology-enhanced learning environment (Manca \& Ranieri, 2013a, 2013b) to facilitate EE. Since social media are only a means of digital technologies, digital platforms, big data, intelligent applications, digital storytelling and other digital methodologies are applied to EE together (Secundo et al., 2020; Sousa, 2019). To conclude, as a vital communication method, social media use in daily life and workplaces and education scenes. Therefore, users are familiar with social networking tools that are easy to accept and adopt. Social media provides text, audio and video message and information for online and blended entrepreneurial learners. Instructors and learners consequently have the initiative to choose an appropriate medium. Hence, the interaction and connections between learner-learner and instructor-learner increase the benefits of active learning and social capital (Gupta \& Bharadwaj, 2013).

\section{Serious games (SGs) in EE}

The idea of SGs lies in the utilization of games and gaming technologies edutainment: not only entertainment but also education and training (Eck, 2006). In other words, SGs bring to learners additional enjoyment (learning by playing or gaming) and simulate different scenarios to enact real-life situations (Susi et al., 2007). Learning entrepreneurial skills via real-life business scenario simulation can avoid and limit real-life risks and damages, reduce the cost when acquiring entrepreneurial skills and competencies. Concerning learning objectives, as opposed to entrepreneurial knowledge (e.g., finance and marketing), SGs develop with more attention toward facilitating entrepreneurial mindset and competencies, especially in innovation, opportunities spotting and risk management (Almeida, 2017). In the second set of articles, 20 of these focused on the effectiveness of SGs in EE. Based on the demand for innovation and experiential entrepreneurial competencies (ConstanţaNicoleta et al., 2015), game designers simulate a real business environment for learners to run a virtual business (Mennecke et al., 2008, 2008) and avoid risks in the real world so that the cost and uncertainty of being entrepreneurs decrease. Except for general effectiveness (Tasnim, 2013), scholars focused on the entrepreneurial mindset, entrepreneurial intention and motivation (Buzady \& Almeida, 2019; Ruiz-Alba et al., 2019), entrepreneurial behavior (Fellnhofer, 2015) and 
entrepreneurial competencies (Williams, 2015). Mayer et al. (2014) narrowed the research subjects into engineering students, which showed gaming experience could significantly influence EE. Furthermore, Bellotti et al. (2014) analyzed the entrepreneurial mindset of engineering students. In general, the relationship between SGs and entrepreneurship intention and skills is positive (Almeida, 2017; Bellotti et al., 2014; Buzady \& Almeida, 2019; Fellnhofer, 2015; Ruiz-Alba et al., 2019), even long-term positive effectiveness (Kriz \& Auchter, 2016). However, the study of Newbery et al. (2016) found a significant negative impact for the authentic learning method, perhaps because students understood the complexity of starting a business (Protopsaltis et al., 2013). Fox et al. (2018) conducted a systematic review on SGs of EE and evaluated games from fidelity, verification and validation in entrepreneurial learning. They argued that SGs had practical value for authentic learning and should be introduced to learners before learners start a business in real-life. However, the real business environment is more ambiguous and lacks nonplayable characters which appear in in-game worlds (Fox et al., 2018), more complex and uncertain than the virtual business world. Entrepreneurial games still lack complexity, uncertainty and interactivity at present to avoid life lessons needed to be experienced by entrepreneurs.

Specific SGs have been applied to EE. Cluster analysis was applied to gameplay experience from 7 aspects to compare TeamUp, Slogan and SimVenture. Compared with TeamUp and Slogan, SimVenture is rich and complex for learners (Mayer et al., 2014). These entrepreneurial games are still found: GoVenture Card Game, the Entrepreneur Card Game, GoVenture: Entrepreneur and Monopoly. Non-digital games are applied in the F2F class, i.e., Monopoly and Slogan. In an online and blended learning environment, digital SGs, e.g., FLIGBY and SimVenture, are growing in popularity at all school levels. Through reviewing the literature, Hot Shot Business, SimVenture, ENTRExplorer and FLIGBY attracted much more attention from scholars and educators in the 2010s. Hot Shot Business is a computer-based entrepreneurship game that was developed by Disney and had been dropped from the website. SimVenture (www.simventure.com) has two simulation games: SimVenture Classic and SimVenture Evolution. As a part of undergraduate and postgraduate modules, SimVenture Evolution is applied in $10 \mathrm{UK}$ universities and colleges, following the principle of 'learn by doing' (Williams, 2015). ENTRExplorer (https:// www.entrexplorer.com/projecto.php) is for immersive entrepreneurs funded by European Commission, simulating a business through 3D and multiplayer. FLIGBY (http://www.Fligby.com) is a web game, especially for leadership learning. Buzady and Almeida (2019) analyzed the function of FLIGBY from 29 indicators, which shows both technical skills and soft skills increased after playing. To adopt an appropriate game, Antonaci et al. (2015) introduced three strategic axes as well as target skills and pedagogical/usability features for instructors and scholars. Educators adopted several SGs for different teaching objectives and context at one online $\mathrm{EE}$, such as business plan, a pilot project of the entrepreneurial idea, market and product analysis as well as evaluation of entrepreneurial skills (Sousa, 2019) course. Concerning the amount of applied SGs, Romero and Usart (2013) utilized two games (Meta Vals and Hot Shot Business) to help learners learn entrepreneurship. Bellotti et al. (2014) analyzed three games (pre-, mid- and post-game) in one-course 
time. Hence, according to the objectives of online EE and phrase, instructors provide plenty of games in class or at home for learners (Antonaci et al., 2015).

SGs are found in MOOCs platforms to increase experiential learning activities as well (Romero \& Usart, 2013). In the web 2.0 learning content management system, each game connects with a specific entrepreneurial task and mini-games are independent of the system (Protopsaltis et al., 2013). Today, SGs simulate a virtual world characterized by avatars and a 3D environment. In a virtual social world, almost every facet imitates real life. For example, gamers start a business, communicate with other avatars and earn virtual currency in Second Life where they acquire a notion of the entrepreneurial process in an e-commerce course (Mennecke, Mcneill, et al., 2008, 2008), whereas establishing too many rules will restrict avatars and lead to low self-presentation in a virtual world (Kaplan \& Haenlein, 2010). In other words, even virtual reality technology or other technologies only simulate the real business, it still a simulated process of being entrepreneurs, which is simplified and idealized. In addition, aims and the phrase of EE courses are the essential consideration for participants to find out the most suitable ones among the present and constantly designed entrepreneurial games. However, we still lack standardized methods and metrics to choose appropriate entrepreneurial SGs. Furthermore, the future trend of SGs will continue to combine with other cutting-edge technologies to simulate starting a business and entertain the process of learning.

\section{Digital platforms in EE}

As a digital educational platform, a course management system or student management system restores and manages data of learning materials, students' performance and interaction data. When starting a discussion, the system automatically distributes questions and team leaders in online World Cafe' (Chang, 2017). The platform facilitates interaction between student-teacher/peer and learning engagement (Wu et al., 2017). Most online learners have sufficient time to finish EE courses and express ideas freely (Kakouris, 2016). EE courses on MOOCs platforms are open, free and many pay a small amount of tuition to get a certificate (e.g., Most courses cost less than 100 euro to get a certificate). Whilst educators and learners can share high-quality learning resources around the world, which is one of the most obvious advantages of digital platforms. Many stellar universities and companies cooperate with MOOCs platforms to upload entrepreneurial courses and resource in the version of the text, audio and video. Almost all of the MOOCs platforms are ondemand video lectures, playing on a mobile phone, tablet and other devices, providing flexible deadlines and self-paced learning (e.g., Udemy). While UNX provided MOOCs (courses are linked with Udemy platform now) for entrepreneurship and community for entrepreneurs or future entrepreneurs mainly in Spain, Portugal and Latin American (Piñuel, 2014), many MOOCs (e.g., Coursera and EdX) platforms set up "entrepreneur or entrepreneurship" sub-model for worldwide learners. Based on the summarization of Baturay (2015) and information on related platforms, 7 common MOOCs management platforms provide EE courses and resource through 
the US and Europe. The detailed information is shown in Table 3 which authors used "entrepreneurship" to collect EE courses until Feb. 25, 2020.

The first three platforms, namely, Coursera, EdX and Udemy have the majority of online EE courses. To quick select suitable courses for learners, based on learners' entrepreneurial learning background, platforms set filter criteria for learners to narrow scope of courses and easily have a suitable start. Since MOOCs are open to learners worldwide, platforms prefer providing English and giving languages options as many as possible. Udemy has the largest amount of entrepreneurship learning products and filter criteria, compared with other 6 platforms. According the components of distance EE courses, at present, it mainly contains on-demand videos, reading materials, exercises, discussion forums, test as well as learning dashboard designed. The content of video focuses on entrepreneurial knowledge framework and skills as well as interview video of successful entrepreneurs. To make MOOCs sustainable development, micro-credentials (acquisition of specific skills) and university credits (Resei et al., 2018) are introduced into MOOCs platforms. Karma, namely digital reputation, is a factor of retention and completion rate related with learners, rewards and interaction (Navío-Marco \& Solórzano-García, 2019). MOOCs combine with interaction to reduce high-rate dropout, e.g., badges, forums, and on-campus students invite online learners to join their teams. Skeptics argue that MOOCs platforms are lack of F2F communication, frequent feedback (Welsh \& Dragusin, 2013) and self-discipline to complete courses (Romero \& Usart, 2013; Vorbach et al., 2019).

Although a large number of courses resource have high enrolment are presented, 5\% course completion rate is typical (Jordan, 2014). A high dropout rate may be unsatisfied with previous online learning experience lack of support services (Ifenthaler \& Yau, 2020). While MOOCs are still the mainstream method to construct online and blended entrepreneurial courses (esp. cheap, easy to access, sophisticated framework and established courses). Hence, we attempt to analyze several common educational technologies introduced into EE, combine with online and blended education to meet the needs of learners for high-quality online entrepreneurship courses and boost course completion rate on digital platforms. In conclusion, a digital system is a choice for spreading EE. Universities and corporations uploaded EE courses on platforms for distributed learners to get entrepreneurshiprelated micro-credentials and degrees. Therefore, instructors and learners easily access worldwide high-quality EE resources without limitation of time and space. While lack of F2F interaction and communication weakens the effectiveness of EE. Therefore, except forums, lecture videos and text materials, platforms are supplied by social networking software (Frederick, 2007; Solórzano-García \& Navío-Marco, 2019), SGs (Romero \& Usart, 2013) and other technologies.

\section{Discussion}

As online and blended entrepreneurial educators, learners and scholars involved, it is necessary to master the advantages and challenges of social media, SGs, digital platforms and their combination. Nevertheless, reviews of educational technologies 


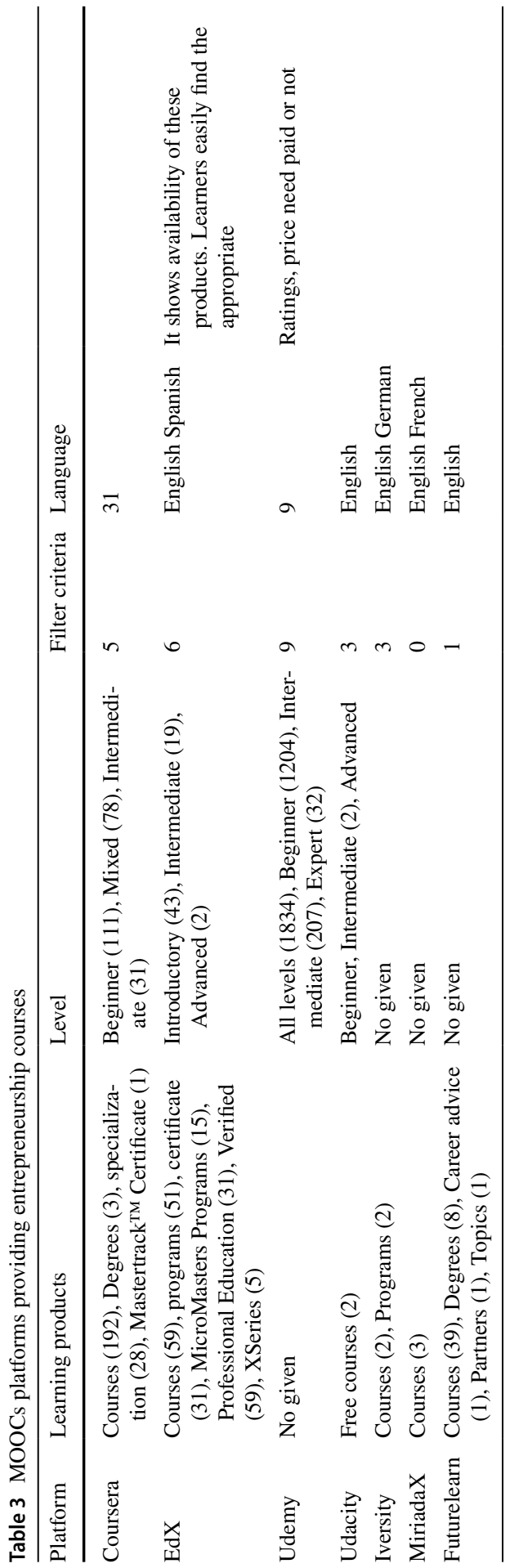


in online and blended EE are still lacking, especially a comparison between them, probably because the F2F method of EE has been dominating the trend. Today, for the pandemic, EE has to transfer into an online and blended environment. Instructors and stakeholders consider educational technologies to facilitate the effectiveness of learning and teaching. Hence, it is time for a systematic review and compares those three technologies mentioned above.

\section{Social media}

Social media is a complimentary resource in professional work (Gruzd and Goertzen, 2013), management education as well as EE (Rueda et al., 2017), since potential entrepreneurship connections and social networks are a success factor for future entrepreneurs. In Italian CLabs, social media is the most leveraged one, compared with big data, digital platforms and other digital technologies (Secundo et al., 2020). learners share learning materials and resources, do teamwork collaborating with others and discuss questions (Ajjan \& Hartshorne, 2008; Mazman \& Usluel, 2010) using various information and communication technologies (ICT) (e.g., text, pictures, audio, video, or a combination). Instructors' effective attendance in social media make better teaching performance (Gruzd et al., 2018), accords with "teacher presence" in an online learning environment (Garrison and Anderson, 2003). However, tutors and chatbots will be a more common alternative for timely feedback because of the overload communication tasks (Fryer et al., 2019). The main function of social media is supporting learning and self-managed learning through boosting learner-to-learner and learner-to-teacher interaction, which produces many shortterm teams (namely, the aim of the team is mainly for EE and teammates are not active after completing the course) and leads to collaborative learning. Liu et al. (2010) explored the Perceived Variables to Technology Acceptance Model (TAM) to research students' intention to use an online learning community. There are five factors (trust, mutual influence, conflict, leadership and cohesion) that impact student knowledge sharing within virtual teams through the synchronous and asynchronous communicational environment (He \& Huang, 2017). Developing trust, making learning contract and making sure membership role differences (Allan \& Lawless, 2003) are necessary for online and blended EE.

Social media with low media richness and weak interaction usually is applied to learn entrepreneurial knowledge. Podcast records short course-related instruction audio for learners' mobile learning. By assigning tasks to every teammate or a team, Wikis content is created by students with a guideline. SNS with lower media richness frequently cooperates with other social media and users communicate asynchronously. For example, learners asynchronously communicate on forums and exchange materials so that their classmates and subsequent learners can learn from existed communication information. The recordings of communication can be leveraged for learning analysis. Learners' comments on the blog were collected to conduct inductive reasoning and analyze the learning effect. To make the congruence between comments and students' reality, student interviews were added (Waghid \& Oliver, 2017). Social networks with strong interaction usually share profiles, information 
and ideas, which probably build a personal relationship and human network for starting a business. As an example of strong interaction and high media richness, a Facebook community can improve the learning effects of writing a business plan through increasing understanding of partner trust and cooperative learning (Chang \& Lee, 2013). Compared with other social tools (e.g., WhatsApp, Line and Twitter), Facebook increased learners' participation even in cross-cultural communication. For example, a Facebook page encourages students to post and follow learning tips so that it facilitates external interaction (Divall \& Kirwin, 2012). Besides, Facebook is an important teaching instrument but not a unique one (Manca \& Ranieri, 2013a). Compared with low rich social media, entrepreneurial learners perceived that Facebook is more popular and effective (Swaramarinda, 2018). However, as reported, Facebook is the fourth most popular social platform for American' youth, compared with YouTube, Instagram and Snapchat (Anderson and Jiang, 2018). In other words, video social media are increasing. Educators should be open to new social media to consider the application possibility of entrepreneurial pedagogy.

Compared with F2F, educators are difficult to get real-time learning feedback in online and blended learning environments, especially in MOOCs platforms. With the application of SNS, learners easily communicate with each other and educatorlearner have more connections. Learning devices easily record and collect learning data of communication, especially plenty of attendees in online learning, which leads to learning analysis that is a technological tendency of the 2020 Horizon report in higher education.

\section{Serious games}

SGs leveraged in EE have the practical experience and theoretical basis. The project of 'Stimulating Entrepreneurship through Serious Games' (eSGs, 2011-2013) was executed in four universities of three countries (Bellotti et al., 2012). As a member of this project, Mayer et al. (2014) analyzed the function of SGs and factors that determine its contributions at Delft University of Technology through qualitative and quantitative methods. Depending on collecting data, which is produced by gamers from devices, SGs are sensitive to analyze data of results and update the functionality to meet the players' requirements and facilitate active learning in time.

SGs make EE courses more interesting and attractive than traditional lectures. However, this doesn't mean the motivation of starting a business will increase after playing a game, even the motivation of females decreased (Kriz \& Auchter, 2016). What cannot be denied is simulating the process of entrepreneurial activities is to identify business opportunities and start-up and marketing strategies (ConstanţaNicoleta et al., 2015). Simulative games make this process attractive. e.g., gamers attend entrepreneurship activities from Second Life which is a simulative business game and they can even use virtual money in the virtual life. Educators encourage and purchase an island on virtual Second Life space for learners to play this game (Mennecke et al., 2008, 2008). While many SGs are stiff and rigid to play with. For example, gamers must follow step by step or skip several steps and they are hard to follow their innovative ideas (e.g., Hot Shot Business). Therefore, compared with 
other video games, simple SGs are not interesting enough and cannot meet their needs. Today, developers have produced more authentic roles in FLIGBY and SimVenture to make games interested and real, such as 3D, simulated market and multiplayers. Consequently, students can acquire learn entrepreneurial skills and behavior more authentically. Educators choose appropriate SGs as teaching tools depending on entrepreneurial teaching objectives and characteristics of games (Antonaci et al., 2015). Also, the application of SGs needs is wider to structure and amend criteria of assessment. Besides, participants and stakeholders pay close attention to technology development directions and trends to apply by SGs. With the expansion of AI, it has been adopted by SGs (e.g., the virtual game world) to facilitate an immersive and virtual learning environment. SGs combine with new technologies, MOOC platforms and social media, which is the near-future scenario. In the virtual game world, players apply social media to their virtual world communication. As an indispensable component in the virtual game world, social media might instead of F2F communication in a virtual learning environment.

\section{Digital platforms}

Learners easily access high-quality entrepreneurial resources, because the collaboration between digital platforms and HEIs makes online EE courses professional and low cost. In contrast with the huge number of learners, the completion rate of entrepreneurial courses on digital platforms is relatively low. For one reason, the competence of self-discipline learning and the strategies of setting own learning pace are necessary for distributed learners. The other main reason is entrepreneurship competence and mindset are achieved through practical activities and interaction amongst learners, which digital platforms are still lacking. Consequently, most EE courses provide online discussion forums to supply online interaction and connection. Instructors usually give topics related to the course to discuss and learners post their puzzles, which improves cooperative and collaboration competence and reduces the dropout rate of courses. All participants with accounts and passwords easily log in to the platform and look for existing entrepreneurship learning resources. Instructors set the "introduce yourself" or "know your classmates" section to know basic information about learners. What's more, instructors appear in the discussion section and their attendance is highlighted (e.g., Coursera). Compared with forums, SNS supports timely contact and feedback. Thereby, digital platforms introduced social media as well, especially in cMOOCs. cMOOCs focus on connection, emphasize social networking and are based on the philosophy of connectivism (Rodriguez, 2013). Social media being another main learning method in cMOOCs comment and enhance interactions and collaboration among global virtual classmates (Kaplan \& Haenlein, 2016). For example, Identifying Entrepreneurial Opportunities by the University of Maryland on EdX provides an extra social media link for learners to know each other. SGs are applied to MOOCs, which make for shortcomings of it, such as engagement (Freire et al., 2014), completion rates and motivation (Borras-Gene et al., 2016) and so on. SGs depend on or are independent of MOOCs platforms. SGs which have a close connection with MOOCs platforms need to 
give feedback beyond "global outcomes" (Freire et al., 2014) and trace multi-level assessment and individual actions to collect more detailed learning data. Cooperating with curriculum designers, SGs which are independent of MOOCs platforms build their platforms. Meanwhile, MOOCs platforms provide an entrance or link for players to $\log$ in to games.

In summary, with the rapid development of MOOCs in the 2010s, many digital platforms provide entrepreneurship videos, exercises and learning materials, combined with forums and workshops, which boost learners international collaboration (Welsh \& Dragusin, 2013) and affect behaviors and skills related with entrepreneurship (Calvo et al., 2019). MOOCs accelerate the accessibility of EE because of flexibility in time and space (Vorbach et al., 2019). Meanwhile, MOOCs platforms provide EE credentials and degrees based on learners' performance to facilitate completion rate (Resei et al., 2018). While the low completion rate of MOOCs needs designers of course provide more support services. Hence, MOOCs platforms flexibly harness social media, SGs and other technologies.

\section{Comparison between the three technologies}

The applications of social media, SGs and digital platforms are comparatively broadly in EE. Evaluating and scoring them depends on the usefulness shown in Table 4. These quality criteria were based on Nielsen (1993), who classified usefulness into usability and utility. Analyzing technical usability (sub-concept of usability) (Hindle, 2002) is easy to master, efficient, easy to remember, few serious errors and user satisfaction. The Utility is whether one can address the needs of the user (Nielsen, 1993; Nokelainen, 2006). Pedagogical usability is a sub-topic of utility. The highest got score 3, the middle got score 2 and the lowest got score 1. Social media were classified into Wiki and Facebook. FLIGBY and SimVenture are illustrations of SGs. Coursera is a research example of digital platforms. Based on every built criterion, the aforementioned five items scored higher than 30 points. From entrepreneurship learning aspects, compared with social media and MOOCs, SGs simulate authentic business scenarios in which learners learn by doing to facilitate entrepreneurial motivation, mindset, competence and participation rate. While SGs got a lower score for lack of systematic design in entrepreneurial knowledge. Whilst Coursera has a good performance in acquiring knowledge. Except for the flexibility of methods, Coursera got the highest score in the teaching area, partly because learning on digital platforms has large similarity with traditional education which educators have a profound experience of didactics. Social media has the best performance in the interaction and cooperation part. Facebook as a social communication tool easily build relationship amongst distributed users. From technical usability aspects, participants are easy to master social media and they need to learn rules to play SGs. Besides, how to use social media is the easiest to remember for users, especially the young generation (namely, Y-generation and Z-generation). However, SGs are the most efficient of the three and their users' satisfaction is the highest, which consistent with the essence of games. Compared with the high error risk of SGs, MOOCs have few errors, since MOOCs need lower-level technology support than SGs. 


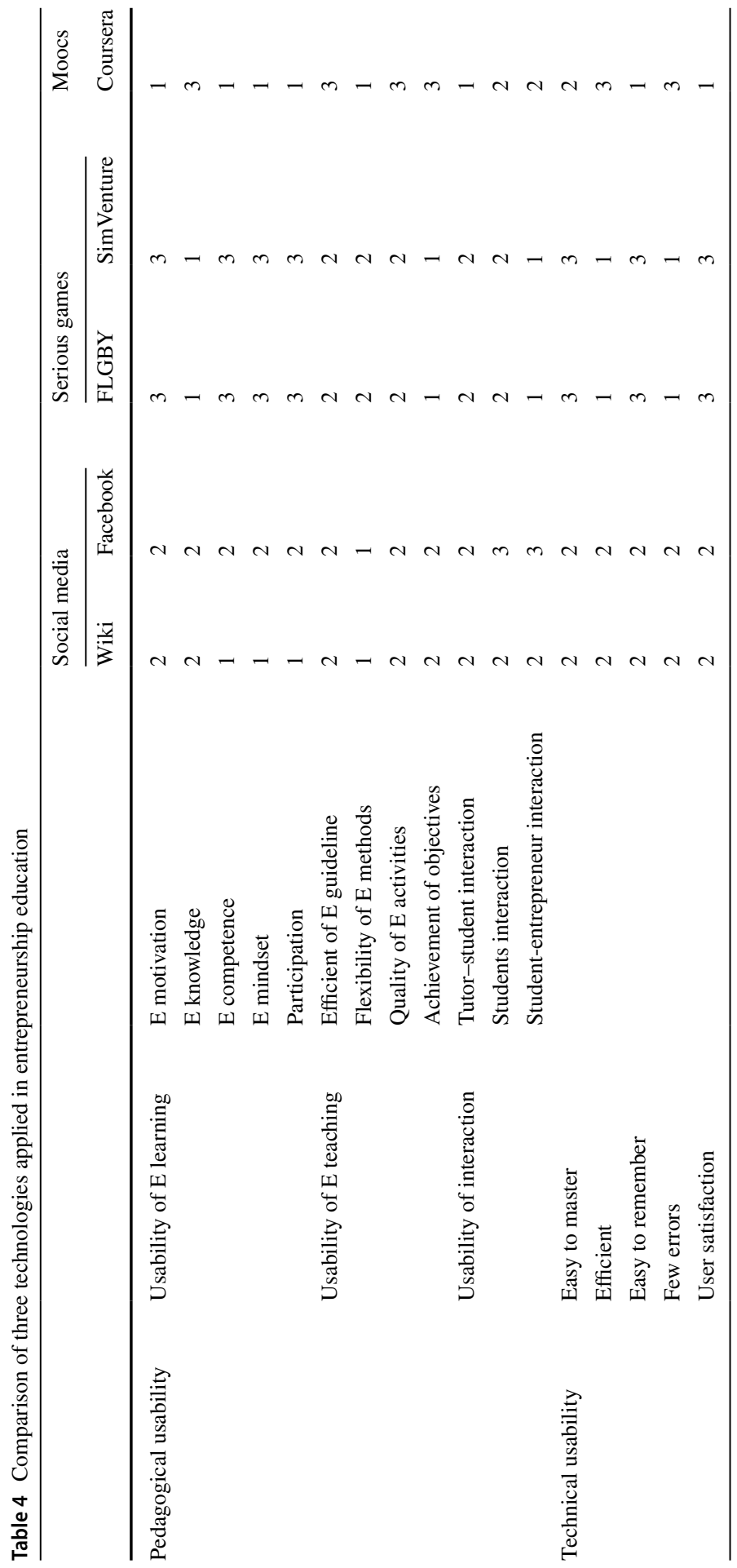


Therefore, social media, SGs and digital platforms have been the most popular technologies applied to online and blended EE until now. All three depend on technology devices to store detailed learning and teaching data that are learning analytics objects. Meanwhile, these technologies are incentive to cutting-edge technologies to update themselves. Social media provide tools to share information, do teamwork and ask and answer questions without being restricted by time and space in EE. SGs make EE more interesting and attractive as well as games simulate real business and reduce costs. MOOCs provide worldwide, free or low-cost learning possibilities. Courses combine social media with SGs to facilitate collaboration and effectiveness. Gamification factors also are added to social media (Wu \& Song, 2019).

This study gathered 121 related to English literature and reviewed 38 published papers. One limitation of this research is still the lack of data. Although the combination between EE and educational technologies is a potential area, the application still is a fresh and ever-changing domain. With the rapid speed of technology development, technicians are adopting another technology possibility to develop application. This research mainly concerns about three relatively mature technologies without those new technologies. The other limitation is the classification of the learning environment. As lacking literature to delimit different terms of learning environment, this research summarizes "online and blended" learning instead of other learning environments.

\section{Conclusion}

Entrepreneurial competence is critical for individual and economic entities. Furthermore, nowadays both in developed countries and developing countries, the knowledge society calls EE in all levels of education, especially in HEIs. Educational technologies accepted by management education have been reviewed in the last two decades worldwide, while educational technologies applied in EE lack systematic review, especially in online and blended entrepreneurial learning as well as teaching. The present study aims to systematically review three popular technologies used in $\mathrm{EE}$ and evaluate the effectiveness in the online and blended learning environment through a comparative method. Compared with the F2F or traditional learning environment, the online and blended EE breaks time and distance limitations. Online learning is a broad definition, which contains e-learning, distance learning and mobile learning. Blended learning is a tendency for higher education institutions and learning corporations. Meanwhile, technological support is provided to promote entrepreneurial learning as well as instruction so that many popular educational technologies came into our view. When collecting literatures, social media, SGs and digital platforms are the most popular adopted educational technologies in EE. For the application of three educational technologies is broad in instructors and learners, published literature focuses on those three technologies more than other technologies.

Regarding social media, which prompts interaction between learner and learner (as well as the learner to instructor), it brings the possibility of online learning, especially ubiquitous learning. Compared with educational technologies 
described in the Horizon Report 2020, social software is mainly used before and after online EE courses for preview and review, since learning platforms and F2F are still the main methods for instruction and active learning in EE. Students' learning data is stored on a computer or other smart devices, which makes it easier to be collected and analyzed than before. Instead of application alone, social media is usually accompanied by other technologies. As technologies develop, social media will be more intelligent and multi-functional for learning analysis soon. SGs make EE more interesting and attractive than courses without SGs. While games simulate real business and base on action orientation, participants learn entrepreneurial motivation, skills and knowledge from experiential scenarios. Learning objectives, phrases of EE courses and learning status are basic considerations for choosing SGs. Meanwhile, scholars should construct and standardize criteria for choosing entrepreneurial games in EE. Participants choose EE courses on MOOCs platforms which have different traits and advantages. Skeptics argued that MOOCs lack F2F interaction, frequent feedback and sufficient support services and self-discipline to complete entrepreneurship courses, while digital platforms facilitate the accessibility of EE because of flexibility in time and distance. And providing entrepreneurial credentials and degrees based on learners' completion and performance. In light of marking these three educational technologies in online and blended EE, every technology has its own characteristics and appropriate relevant educational scenes.

In general, this study has identified digital platforms that provide worldwide, free or pay little and non-F2F learning possibilities, combined with social media to enhance interaction and SGs to increase engagement, completion rate and motivation. With the appearance of cutting-edge technologies, educational technologies in EE need to update technologies and consolidate theoretical underpinning (namely both technologies and pedagogy). One main objective of educational technologies in EE is facilitating individual and collaborative competencies. This study appears to be the first study to compare social media, SGs and digital platforms used in EE to evaluate the effectiveness and challenges they need to face. For making sure EE and business education more authentic, attractive, convenient, effective and efficient, a further study will focus on the concrete effects of the three technologies with AI to facilitate entrepreneurial collaborative competencies in an online and blended learning environment.

Funding Open Access funding enabled and organized by Projekt DEAL.

\section{Declarations}

Conflict of interest The authors declare that they have no conflict of interest.

Ethical approval All procedures performed in studies involving human participants were in accordance with the ethical standards of the institutional and/or national research committee and with the 1964 Helsinki Declaration and its later amendments or comparable ethical standards. This article does not contain any studies with animals performed by any of the authors. 
Informed consent Informed consent was obtained from all individual participants included in the study. Additional informed consent was obtained from all individual participants for whom identifying information is included in this article.

Open Access This article is licensed under a Creative Commons Attribution 4.0 International License, which permits use, sharing, adaptation, distribution and reproduction in any medium or format, as long as you give appropriate credit to the original author(s) and the source, provide a link to the Creative Commons licence, and indicate if changes were made. The images or other third party material in this article are included in the article's Creative Commons licence, unless indicated otherwise in a credit line to the material. If material is not included in the article's Creative Commons licence and your intended use is not permitted by statutory regulation or exceeds the permitted use, you will need to obtain permission directly from the copyright holder. To view a copy of this licence, visit http://creativecommons.org/licen ses/by/4.0/.

\section{References}

Acs, Z., Szerb, L., \& Autio, E. (2018). The Global Entrepreneurship Index. In Z. Acs, L. Szerb, \& E. Autio (Eds.), Global Entrepreneurship and Development Index. (pp. 19-38). Berlin: Springer. https://doi.org/10.1007/978-3-319-63844-7_3.

Ajjan, H., \& Hartshorne, R. (2008). Investigating faculty decisions to adopt Web 2.0 technologies: Theory and empirical tests. The Internet and Higher Education, 11(2), 71-80. https://doi.org/10. 1016/j.iheduc.2008.05.002.

Akhmetshin, E., Kuderova, I., Ryumshin, A., Gayazova, S. R., Romanova, E. V., \& Erzinkyan, E. (2019). Entrepreneurial skills development through distance learning. Journal of Entrepreneurship Education, 22.

Al-atabi, M., \& Deboer, J. (2014). Author's personal copy technovation teaching entrepreneurship using massive open online course (MOOC) Author's personal copy. 34, 261-264.

Ali, M. M., Hashim, N., \& Ibrahim, A. (2017). The evaluations of facebook as an educational technology tools in polytechnic's entrepreneurship courses. Journal of Fundamental and Applied Sciences, 9(6S), 805. https://doi.org/10.4314/jfas.v9i6s.60.

Allan, J., \& Lawless, N. (2003). Stress caused by on-line collaboration in e-learning: A developing model. Education + Training, 45(8), 564-572. https://doi.org/10.1108/00400910310508955.

Allen, I. E., \& Seaman, J. (2008). Staying the course: Online education in the United States, 2008. Ultrasound in Obstetrics and Gynecology, 21(1), 13-14. https://doi.org/10.1002/uog.35.

Almeida, F. L. (2017). Experience with entrepreneurship learning using serious games. Cypriot Journal of Educational Sciences, 12(2), 69-80. https://doi.org/10.18844/cjes.v12i2.1939.

Alon, I., \& Herath, R. K. (2014). Teaching international business via social media projects. Journal of Teaching in International Business, 25(1), 44-59. https://doi.org/10.1080/08975930.2013.847814.

Anderson, M., \& Jiang, J. (2018). Teens, social media \& technology 2018. 10.

Antonaci, A., Dagnino, F. M., Ott, M., Bellotti, F., Berta, R., De Gloria, A., Lavagnino, E., Romero, M., Usart, M., \& Mayer, I. (2015). A gamified collaborative course in entrepreneurship: Focus on objectives and tools. Computers in Human Behavior, 51, 1276-1283. https://doi.org/10.1016/j.chb. 2014.11.082.

Arbaugh, J. B., Desai, A., Rau, B., \& Sridhar, B. S. (2010). A review of research on online and blended learning in the management disciplines: 1994-2009. Organization Management Journal, 7(1), 39-55.

Arbaugh, J. B., Godfrey, M. R., Johnson, M., Pollack, B. L., Niendorf, B., \& Wresch, W. (2009). Research in online and blended learning in the business disciplines: Key findings and possible future directions. The Internet and Higher Education, 12(2), 71-87. https://doi.org/10.1016/j.iheduc.2009.06. 006.

Bacigalupo, M., Kampylis,P., P., Punie, Y., \& Van den Brande, G. (2016). EntreComp: The entrepreneurship competence framework. Publications Office. https://data.europa.eu/doi/https://doi.org/10. 2791/593884 
Bae, T. J., Qian, S., Miao, C., \& Fiet, J. O. (2014). The relationship between entrepreneurship education and entrepreneurial intentions: A meta-analytic review. Entrepreneurship: Theory and Practice, 38(2), 217-254. https://doi.org/10.1111/etap.12095.

Barczyk, C. C., \& Duncan, D. G. (2012). Social networking media: An approach for the teaching of international business. Journal of Teaching in International Business, 23(2), 98-122. https:// doi.org/10.1080/08975930.2012.718703.

Barkham, R. J. (1994). Entrepreneurial characteristics and the size of the new firm: A model and an econometric test. Small Business Economics, 6(2), 117-125. https://doi.org/10.1007/BF010 65184.

Barringer, B. R., Jones, F. F., \& Neubaum, D. O. (2005). A quantitative content analysis of the characteristics of rapid-growth firms and their founders. Journal of Business Venturing, 20(5), 663687. https://doi.org/10.1016/j.jbusvent.2004.03.004.

Baturay, M. H. (2015). An overview of the world of MOOCs. Procedia-Social and Behavioral Sciences, 174, 427-433. https://doi.org/10.1016/j.sbspro.2015.01.685.

Bellotti, F., Berta, R., De Gloria, A., Lavagnino, E., Antonaci, A., Dagnino, F., Ott, M., Romero, M., Usart, M., \& Mayer, I. S. (2014). Serious games and the development of an entrepreneurial mindset in higher education engineering students. Entertainment Computing, 5(4), 357-366. https://doi.org/10.1016/j.entcom.2014.07.003.

Bellotti, F., Berta, R., De Gloria, A., Lavagnino, E., Dagnino, F., Ott, M., Romero, M., Usart, M., \& Mayer, I. S. (2012). Designing a course for stimulating entrepreneurship in higher education through serious games. Procedia Computer Science, 15, 174-186. https://doi.org/10.1016/j. procs.2012.10.069.

Blaschke, L. M. (2014). Using social media to engage and develop the online learner in self-determined learning. Research in Learning Technology. https://doi.org/10.3402/rlt.v22.21635.

Bonk, C. J., \& Graham, C. R. (2004). Blended learning systems: Definition, current trends, and future directions. Guangxue Jishu/Optical Technique, 30(6), 717.

Borras-Gene, O., Martiñez-nunez, M., \& Fidalgo-Blanco, Á. (2016). New challenges for the motivation and learning in engineering education using gamification in MOOC. International Journal of Engineering Education, 32(1), 501-512.

Brooks, C., Vorley, T., \& Gherhes, C. (2019). Entrepreneurial ecosystems in Poland: Panacea, paper tiger, or Pandora's box? Journal of Entrepreneurship and Public Policy, 8(3), 319-338. https:// doi.org/10.1108/JEPP-04-2019-0036.

Buzady, Z., \& Almeida, F. (2019). FLIGBY-A serious game tool to enhance motivation and competencies in entrepreneurship. Informatics. https://doi.org/10.3390/informatics6030027.

Calvo, S., Morales, A., \& Wade, J. (2019). The use of MOOCs in social enterprise education: An evaluation of a North-South collaborative FutureLearn program. Journal of Small Business and Entrepreneurship, 31(3), 201-223. https://doi.org/10.1080/08276331.2018.1453241.

Chandra, Y., \& Leenders, M. A. A. M. (2012). User innovation and entrepreneurship in the virtual world: A study of Second Life residents. Technovation, 32(7-8), 464-476. https://doi.org/10. 1016/j.technovation.2012.02.002.

Chang, W. L. (2017). Online training for business plan writing through the World Café method: The roles of leadership and trust. Universal Access in the Information Society, 16(2), 313-324. https://doi.org/10.1007/s10209-016-0459-y.

Chang, W. L., \& Lee, C. Y. (2013). Trust as a learning facilitator that affects students' learning performance in the Facebook community: An investigation in a business planning writing course. Computers and Education, 62, 320-327. https://doi.org/10.1016/j.compedu.2012.11.007.

Cheng, Y. M., Chan, S. W., \& Mahmood, A. (2009). The effectiveness of entrepreneurship education in Malaysia. Education+Training, 51(7), 555-566.

Cirulli, F., Cirulli, F., Elia, G., Lorenzo, G., \& Margherita, A. (2016). The use of MOOCs to support personalized learning: An application in the technology entrepreneurship field. Knowledge Management and E-Learning Application in the Technology Entrepreneurship Fields, 8(1), $109-123$.

Constanţa-Nicoleta, B., Radu Ioan, M., Maria-Iuliana, D., Augustin, P., \& Narcisa Georgeta, C. (2015). Simulation-based E-learning framework for entrepreneurship education and training. Amfiteatru Economic Journal, 17(38), 10-24.

Dabbagh, N., \& Kitsantas, A. (2012). Personal learning environments, social media, and self-regulated learning: A natural formula for connecting formal and informal learning. The Internet and Higher Education, 15(1), 3-8. https://doi.org/10.1016/j.iheduc.2011.06.002. 
Divall, M. V., \& Kirwin, J. L. (2012). Using facebook to facilitate course-related discussion between students and faculty members. American Journal of Pharmaceutical Education, 76(2), 1-5. https:// doi.org/10.5688/ajpe76232.

Eck, R. V. (2006). Digital game-based learning: It's not just the digital natives who are restless. EDUCAUSE Review, 41, 16.

Faria, A. J., Hutchinson, D., Wellington, W. J., \& Gold, S. (2009). Developments in business gaming: A review of the past 40 years. Simulation and Gaming, 40(4), 464-487. https://doi.org/10.1177/ 1046878108327585.

Fayolle, A. (2008). Entrepreneurship education at a crossroads: Towards a more mature teaching field. Journal of Enterprising Culture, 16(04), 325-337. https://doi.org/10.1142/S0218495808000211.

Fayolle, A. (2013). Personal views on the future of entrepreneurship education. A Research Agenda for Entrepreneurship Education, 25(May), 127-138. https://doi.org/10.4337/9781786432919.00013.

Fellnhofer, K. (2015). Changing entrepreneurial intention and behavior: A digital game-based learning environment dedicated to entrepreneurship education. Journal for International Business and Entrepreneurship Development, 8(4), 378. https://doi.org/10.1504/jibed.2015.072938.

Fellnhofer, K. (2018). Game-based entrepreneurship education: impact on attitudes, behaviors and intentions. World Review of Entrepreneurship, Management and Sustainable Development, 14(1/2), $205-228$.

Fiet, J. O. (2001). The theoretical side of teaching entrepreneurship. Journal of Business Venturing, 16(1), 1-24. https://doi.org/10.1016/S0883-9026(99)00041-5.

Fox, J., Pittaway, L., \& Uzuegbunam, I. (2018). Simulations in entrepreneurship education: Serious games and learning through play. Entrepreneurship Education and Pedagogy, 1, 61-89.

Frederick, H. (2007). Blended learning in entrepreneurship education in the Asia-Pacific: A grounded theory approach to entrepreneurship pedagogy. Deakin Research Online, pp. 1-16.

Freire, M., Del Blanco, Á., \& Fernańdez-Manjón, B. (2014). Serious games as edX MOOC activities. In IEEE global engineering education conference, EDUCON, April. (pp. 867-871). https://doi. org/https://doi.org/10.1109/EDUCON.2014.6826198

Fryer, L. K., Nakao, K., \& Thompson, A. (2019). Chatbot learning partners: Connecting learning experiences, interest and competence. Computers in Human Behavior, 93, 279-289. https://doi.org/10. 1016/j.chb.2018.12.023.

Gibb, A. (2002). In pursuit of a new "enterprise" and "entrepreneurship" paradigm for learning: Creative destruction, new values, new ways of doing things and new combinations of knowledge. International Journal of Management Reviews, 4(3), 233-269. https://doi.org/10.1111/1468-2370.00086.

Grivokostopoulou, F., Kovas, K., \& Perikos, I. (2019). Examining the impact of a gamified entrepreneurship education framework in higher education. Sustainability (Switzerland). https://doi.org/10. 3390/su11205623.

Gruzd, A., Haythornthwaite, C., Paulin, D., Gilbert, S., \& del Valle, M. E. (2018). Uses and gratifications factors for social media use in teaching: Instructors' perspectives. New Media \& Society, 20(2), 475-494. https://doi.org/10.1177/1461444816662933.

Gupta, N., \& Bharadwaj, S. S. (2013). Agility in business school education through richness and reach: A conceptual model. Education + Training, 55, 370-384.

Hauge, J., Bellotti, F., Berta, R., Brandao Carvalho, M., De Gloria, A., Lavagnino, E., et al. (2013). Field assessment of serious games for entrepreneurship in higher education. Journal of Convergence Information Technology, 8(13), 1-12.

He, J., \& Huang, X. (2017). Collaborative online teamwork: Exploring students' satisfaction and attitudes with google hangouts as a supplementary communication tool. Journal of Research on Technology in Education, 49(3-4), 149-160. https://doi.org/10.1080/15391523.2017.1327334.

Henry, C., Hill, F., \& Leitch, C. (2005). Entrepreneurship education and training: Can entrepreneurship be taught? Part I. Education and Training, 47(2), 98-111. https://doi.org/10.1108/0040091051 0586524.

Hindle, K. (2002). A grounded theory for teaching entrepreneurship using simulation games. Simulation \& Gaming, 33, 236-241.

Holinska, T., Komarovska, O., Melnyk, O., Petko, L., Shpitsa, R., Sova, O., \& Strohal, T. (2019). Cloud technologies in art entrepreneurship education. Journal of Entrepreneurship Education, 22, 1-6.

Honjo, Y. (2004). Growth of new start-up firms: Evidence from the Japanese manufacturing industry. Applied Economics, 36(4), 343-355. https://doi.org/10.1080/00036840410001674277.

Huang-Saad, A. Y., Morton, C. S., \& Libarkin, J. C. (2018). Entrepreneurship assessment in higher education: A research review for engineering education researchers: entrepreneurship assessment in 
higher education. Journal of Engineering Education, 107(2), 263-290. https://doi.org/10.1002/jee. 20197.

Hytti, U., \& O'Gorman, C. (2004). What is "enterprise education"? An analysis of the objectives and methods of enterprise education programmes in four European countries. Education + Training, 46(1), 11-23. https://doi.org/10.1108/00400910410518188.

Ifenthaler, D., \& Yau, J.Y.-K. (2020). Utilising learning analytics to support study success in higher education: A systematic review. Educational Technology Research and Development, 68(4), 19611990. https://doi.org/10.1007/s11423-020-09788-z.

Januszewski, A. \& Molenda, M. (2013). Educational Technology: A definition with commentary. In Journal of Chemical Information and Modeling (Vol. 53, Issue 9). https://doi.org/https://doi.org/ 10.1017/CBO9781107415324.004.

Jones, B., \& Iredale, N. (2009). Entrepreneurship education and Web 2.0. Journal of Research in Marketing and Entrepreneurship, 11(1), 66-77. https://doi.org/10.1108/14715200911014158.

Jones, C. (2010). Entrepreneurship education: Revisiting our role and its purpose. Journal of Small Business and Enterprise Development, 17(4), 500-513. https://doi.org/10.1108/14626001011088697.

Jordan, K. (2014). Initial trends in enrolment and completion of massive open online courses. The International Review of Research in Open and Distributed Learning, 15(1), 8. https://doi.org/10.19173/ irrodl.v15i1.1651.

Josien, L., \& Sybrowsky, J. (2013). Teaching entrepreneurship in action: Using Ebay as an enducational tool. Journal of Entrepreneurship Education, 16(2013), 1-11.

Kakouris, A. (2016). Multidimensional Learning Environments for Entrepreneurship Education. In Proceedings of The 11th European Conference on Innovation and Entrepreneurship, Jyvaskyla, Finland (pp. 344-349).

Kaplan, A. M., \& Haenlein, M. (2010). Users of the world, unite! The challenges and opportunities of Social Media. Business Horizons, 53(1), 59-68. https://doi.org/10.1016/j.bushor.2009.09.003.

Kaplan, A. M., \& Haenlein, M. (2016). Higher education and the digital revolution: About MOOCs, SPOCs, social media, and the Cookie Monster. Business Horizons, 59(4), 441-450. https://doi.org/ 10.1016/j.bushor.2016.03.008.

Karimi, S., \& Chizari, M. (2010). Entrepreneurship education in Iranian higher education: The current state and challenges. European Journal of Scientific Research, 48, 35-50.

Kassean, H., Vanevenhoven, J., Liguori, E., \& Winkel, D. E. (2015). Entrepreneurship education: A need for reflection, real-world experience and action. International Journal of Entrepreneurial Behavior and Research, 21(5), 690-708. https://doi.org/10.1108/IJEBR-07-2014-0123.

Keeling, R. (2006). The bologna process and the Lisbon research agenda: The European commission's expanding role in higher education discourse. European Journal of Education, 41(2), 203-223. https://doi.org/10.1111/j.1465-3435.2006.00256.x.

Kietzmann, J. H., Hermkens, K., McCarthy, I. P., \& Silvestre, B. S. (2011). Social media? Get serious! Understanding the functional building blocks of social media. Business Horizons, 54(3), 241-251. https://doi.org/10.1016/j.bushor.2011.01.005.

Kriz, W. C., \& Auchter, E. (2016). 10 Years of evaluation research into gaming simulation for german entrepreneurship and a new study on its long-term effects. Simulation and Gaming, 47(2), 179205. https://doi.org/10.1177/1046878116633972.

Kuratko, D. F. (2005). The Emergence of Entrepreneurship Education: Development, Trends and Challenges. Entrepreneurship Theory \& Practice, 29(5), 577-597.

Lackéus, M., \& Middleton, K. W. (2015). Venture creation programs: Bridging entrepreneurship education and technology transfer. Education + Training, 57(1), 48-73. https://doi.org/10.1108/ ET-02-2013-0013.

Lameras, P., Tsiatsos, T., Petridis, P., Tolis, D., Liarokapis, F., Anastasiadou, D., Protopsaltis, A., Hendrix, M., \& Arnab, S. (2015). Creative thinking experimentations for entrepreneurship with a disruptive, personalised and mobile game-based learning ecosystem. In 2015 International Conference on Interactive Mobile Communication Technologies and Learning (IMCL), Thessaloniki, Greece, 348-352.

Liguori, E., \& Winkler, C. (2020). From offline to online: Challenges and opportunities for entrepreneurship education following the COVID-19 pandemic. Entrepreneurship Education and Pedagogy, 3(4), 346-351. https://doi.org/10.1177/2515127420916738.

Liñán, F. (2004). Intention-based models of entrepreneurship education. Piccola Impresa/Small Business, 2004(3), 11-35. 
Liu, I. F., Chen, M. C., Sun, Y. S., Wible, D., \& Kuo, C. H. (2010). Extending the TAM model to explore the factors that affect intention to use an online learning community. Computers and Education, 54(2), 600-610. https://doi.org/10.1016/j.compedu.2009.09.009.

Löbler, H. (2006). Learning entrepreneurship from a constructivist perspective. Technology Analysis and Strategic Management, 18(1), 19-38. https://doi.org/10.1080/09537320500520460.

Man, T. W. Y., Lau, T., \& Chan, K. F. (2002). The competitiveness of small and medium enterprises: A conceptualization with focus on entrepreneurial competencies. Journal of Business Venturing, 17, $123-142$.

Manca, S., \& Ranieri, M. (2013). Is it a tool suitable for learning? A critical review of the literature on Facebook as a technology-enhanced learning environment: Is Facebook a tool suitable for learning? Journal of Computer Assisted Learning, 29(6), 487-504. https://doi.org/10.1111/jcal.12007.

Manca, S., \& Ranieri, M. (2013). Is it a tool suitable for learning? A critical review of the literature on Facebook as a technology-enhanced learning environment. Journal of Computer Assisted Learning, 29(6), 487-504. https://doi.org/10.1111/jcal.12007.

Maritz, A., Jones, C., \& Shwetzer, C. (2015). The status of entrepreneurship education in Australian universities. Education + Training, 57(8/9), 1020-1035. https://doi.org/10.1108/ET-04-2015-0026.

Martin, B. C., McNally, J. J., \& Kay, M. J. (2013). Examining the formation of human capital in entrepreneurship: A meta-analysis of entrepreneurship education outcomes. Journal of Business Venturing, 28(2), 211-224. https://doi.org/10.1016/j.jbusvent.2012.03.002.

Mayer, I., Kortmann, R., Wenzler, I., Wetters, Á., \& Spaans, J. (2014). Game-Based entrepreneurship education: Identifying enterprising personality, motivation and intentions amongst engineering students. Journal of Entrepreneurship Education, 17(2), 217-244.

Mager, U., \& Nowak, P. (2012). Effects of student participation in decision making at school. A systematic review and synthesis of empirical research. Educational Research Review, 7(1), 38-61. https:// doi.org/10.1016/j.edurev.2011.11.001.

Mazman, S. G., \& Usluel, Y. K. (2010). Modeling educational usage of Facebook. Computers \& Education, 55, 444-453.

McLoughlin, C., \& Lee, M. J. W. (2010). Personalised and self regulated learning in the Web 2.0 era: International exemplars of innovative pedagogy using social software. Australasian Journal of Educational Technology, 26(1), 28-43. https://doi.org/10.14742/ajet.1100.

Menkhoff, T., \& Bengtsson, M. L. (2012). Engaging students in higher education through mobile learning: Lessons learnt in a Chinese entrepreneurship course. Educational Research for Policy and Practice, 11(3), 225-242. https://doi.org/10.1007/s10671-011-9123-8.

Mennecke, B., Hassall, L. M., \& Triplett, J. (2008). The mean business of second life: Teaching entrepreneurship, technology and e-commerce in immersive environments. MERLOT Journal of Online Teaching and Learning, 4(3), 339-348.

Mennecke, B. E., Mcneill, D., Ganis, M., Roche, E. M., \& Bray, D. A. (2008). Second life and other virtual worlds: A roadmap for research. In Supply chain and information systems publications (Vol. 3).

Mitchelmore, S., \& Rowley, J. (2013). Entrepreneurial competencies of women entrepreneurs pursuing business growth. Journal of Small Business and Enterprise Development, 20(1), 125-142. https:// doi.org/10.1108/14626001311298448.

Moore, J. L., Dickson-Deane, C., \& Galyen, K. (2010). E-Learning, online learning, and distance learning environments: Are they the same? Internet and Higher Education, 14(2), 129-135. https://doi. org/10.1016/j.iheduc.2010.10.001.

Navío-Marco, J., \& Solórzano-García, M. (2019). Student's social e-reputation ("karma”) as motivational factor in MOOC learning. Interactive Learning Environments. https://doi.org/10.1080/10494820. 2019.1579237.

Newbery, R., Lean, J., \& Moizer, J. (2016). Evaluating the impact of serious games: The effect of gaming on entrepreneurial intent. Information Technology and People, 29(4), 733-749. https://doi.org/10. 1108/ITP-05-2015-0111.

Ngoc Khuong, M., \& Huu An, N. (2016). The Factors affecting entrepreneurial intention of the students of Vietnam National University-A mediation analysis of perception toward entrepreneurship. Journal of Economics, Business and Management, 4(2), 104-111. https://doi.org/10.7763/joebm. 2016.v4.375.

Nielsen, J. (1993). Usability engineering. In Lecture notes in computer science (Including subseries lecture notes in artificial intelligence and lecture notes in bioinformatics), 4970 LNCS (pp. 527-554). https://doi.org/10.1007/978-3-540-70552-9_21 
Nisheva, M., Gourova, E., \& Antonova, A. (2009). ICT and entrepreneurship skills at FMI. In: 8.

Nokelainen. (2006). Interoperability of educational systems-Editorial of special issue. Educational Technology and Society, 9(2), 1-3.

O’Brien, B. C., Harris, I. B., Beckman, T. J., Reed, D. A., \& Cook, D. A. (2014). Standards for reporting qualitative research: A synthesis of recommendations. Academic Medicine, 89(9), 12451251. https://doi.org/10.1097/ACM.0000000000000388.

Obschonka, M., \& Audretsch, D. B. (2020). Artificial intelligence and big data in entrepreneurship: A new era has begun. Small Business Economics, 55(3), 529-539. https://doi.org/10.1007/ s11187-019-00202-4.

Okoli, C. (2015). A guide to conducting a standalone systematic literature review. Communications of the Association for Information Systems, 37(1), 879-910. https://doi.org/10.17705/1cais.03743.

Oosterbeek, H., van Praag, M., \& Ijsselstein, A. (2010). The impact of entrepreneurship education on entrepreneurship skills and motivation. European Economic Review, 54(3), 442-454. https:// doi.org/10.1016/j.euroecorev.2009.08.002.

Petridou, E., \& Sarri, K. (2011). Developing "potential entrepreneurs" in higher education institutes. Journal of Enterprising Culture, 19, 79-99.

Piñuel, M. C. (2014). UNX: A Latin American Community of Knowledge for Entrepreneurship. The International Journal for Innovation and Quality in Learning, 3(3), 100-106.

Protopsaltis, A., Hainey, T., Borosis, S., Connolly, T., \& Copado, J. (2013). StartUP_EU: Using game-based learning and Web 2.0 technologies to teach entrepreneurship to secondary education students. 14.

Protopsaltis, A., Hetzner, S., Borotis, S., Connolly, T., \& Hainey, T. (2014). How to teach entrepreneurship using serious games and web 2.0. In Proceedings-IEEE 14th international conference on advanced learning technologies, ICALT 2014 (pp. 227-229). https://doi.org/https://doi. org/10.1109/ICALT.2014.72

Purzer, E., \& Fila, N. (2016). Evaluation of current assessment methods in engineering entrepreneurship education. Entrepreneurship Education, 27.

Rahim, H. L., Kamaruddin, M., Lajin, N. F. M., Buyong, S. Z., \& Bakri, A. A. (2015). Entrepreneurship education in Malaysia: A critical review. Journal of Technology Management and Business, 02(02), 11.

Rashid, L. (2019). Entrepreneurship education and sustainable development goals: A literature review and a closer look at fragile states and technology-enabled approaches. Sustainability, 11(19), 5343. https://doi.org/10.3390/su11195343.

Rasmussen, E. A., \& Sørheim, R. (2006). Action-based entrepreneurship education. Technovation, 26(2), 185-194. https://doi.org/10.1016/j.technovation.2005.06.012.

Ratten, V. (2013). Cloud computing: A social cognitive perspective of ethics, entrepreneurship, technology marketing, computer self-efficacy and outcome expectancy on behavioural intentions. Australasian Marketing Journal (AMJ), 21(3), 137-146. https://doi.org/10.1016/j.ausmj.2013. 02.008 .

Reid, A., \& Gilmore, A., Kolb, A., Stefan, K., Jauhola, E. (2018). Internationalization of entrepreneurial marketing education: Three Nations project.

Resei, C., Friedl, C., \& Żur, A. (2018). MOOCs and entrepreneurship education-contributions, opportunities and gaps. International Entrepreneurship Review, 4(3), 151-166.

Rippa, P. (2018). Digital academic entrepreneurship-The potential of digital technologies on academic entrepreneurship. Technological Forecasting, 146, 900-911.

Robinson, S., Neergaard, H., Tanggaard, L., \& Krueger, N. F. (2016). New horizons in entrepreneurship education: From teacher-led to student-centered learning. Education + Training, 58(7/8), 661-683. https://doi.org/10.1108/ET-03-2016-0048.

Rodriguez, O. (2013). The concept of openness behind $\mathrm{c}$ and x-MOOCs (massive open online courses). Open Praxis, 5(1), 67-73. https://doi.org/10.5944/openpraxis.5.1.42.

Romero, M., \& Usart, M. (2013). Serious games integration in an entrepreneurship Massive Online Open Course (MOOC). In: Lecture notes in computer science (including subseries lecture notes in artificial intelligence and lecture notes in bioinformatics), 8101 LNCS (pp. 212-225). https:// doi.org/10.1007/978-3-642-40790-1_21

Rueda, L., Benitez, J., \& Braojos, J. (2017). From traditional education technologies to student satisfaction in management education: A theory of the role of social media applications. Information and Management, 54(8), 1059-1071. https://doi.org/10.1016/j.im.2017.06.002. 
Ruiz-Alba, J. L., Soares, A., Rodríguez-Molina, M. A., \& Banoun, A. (2019). Gamification and entrepreneurial intentions. Journal of Small Business and Enterprise Development, 26(5), 661-683. https:// doi.org/10.1108/JSBED-09-2018-0266.

Schlaegel, C., \& Koenig, M. (2014). Determinants of entrepreneurial intent: Ameta-analytic test and integration of competing models. Entrepreneurship: Theory and Practice, 38(2), 291-332.

Secundo, G., Rippa, P., \& Meoli, M. (2020). Digital transformation in entrepreneurship education centers-preliminary evidence from the Italian Contamination Labs network, 17.

Seikkula-Leino, J., Ruskovaara, E., Ikavalko, M., Mattila, J., \& Rytkola, T. (2010). Promoting entrepreneurship education: The role of the teacher? Education + Training, 52(2), 117-127. https://doi.org/ $10.1108 / 00400911011027716$.

Sexton, D. L., \& Bowman, N. B. (1984). Entrepreneurship education: Suggestions for increasing effectiveness. Journal of Small Business Management, 22(2), 18-25. https://doi.org/10.1016/j.jaci.2012. 05.050 .

Siemens, G., \& Tittenberger, P. (2009). Handbook of emerging technologies for learning. In: Image Rochester NY, 65.

Solórzano-García, M., \& Navío-Marco, J. (2019). Developing social entrepreneurs through distance education: The value of commitment and interactivity with the learning community. 21.

Sousa, M. J. (2019). Creating knowledge and entrepreneurial capacity for HE students with digital education methodologies: Differences in the perceptions of students and entrepreneurs. Journal of Business Research, 94, 227-240.

Susi, T., Johannesson, M., Backlund, P. (2007). Serious Games: An overview. In: 2017 IEEE 8th annual ubiquitous computing, electronics and mobile communication conference, UEMCON 2017, 2018Janua (pp. 488-491). https://doi.org/10.1109/UEMCON.2017.8249059

Swaramarinda, D. R. (2018). The usefulness of information and communication technology in entrepreneurship subject. Journal of Entrepreneurship Education, 21(3), 10.

Tarabasz, A., Selaković, M., \& Abraham, C. (2018). The classroom of the future: Disrupting the concept of contemporary business education. 17.

Tasnim, R. (2013). Playing entrepreneurship: Can games make a difference? 15.

Tess, P. A. (2013). The role of social media in higher education classes (real and virtual)-A literature review. Computers in Human Behavior, 29(5), A60-A68. https://doi.org/10.1016/j.chb.2012.12. 032.

Toledo, I., Albornoz, C., \& Schneider, K. (2020). Learning analytics to explore dropout in online entrepreneurship education. Psychology, 11(02), 268-284. https://doi.org/10.4236/psych.2020.112017.

Tong, A., Sainsbury, P., \& Craig, J. (2007). Consolidated criteria for reporting qualitative research (COREQ): A 32-item checklist for interviews and focus groups. International Journal for Quality in Health Care, 19(6), 349-357. https://doi.org/10.1093/intqhc/mzm042.

Udosen, I., \& Upula, B. (2019). Utilization of Blogging Platforms and Acquisition of Entrepreneurial Skills for Self-Reliance Among Educational Technology Students in University of Calabar. Modern Applied Science, 13(6), 60-67.

Vesper, K. H., \& Gartner, W. B. (1997). Measuring progress in entrepreneurship education. Journal of Business Venturing, 12(5), 403-421. https://doi.org/10.1016/S0883-9026(97)00009-8.

von Graevenitz, G., Harhoff, D., \& Weber, R. (2010). The effects of entrepreneurship education. Journal of Economic Behavior and Organization, 76(1), 90-112. https://doi.org/10.1016/j.jebo.2010. 02.015 .

Vorbach, S., Maria Poandl, E., \& Korajman, I. (2019). Digital entrepreneurship education: The role of MOOCs. International Journal of Engineering Pedagogy, 9(3), 99-111. https://doi.org/10.3991/ ijep.v9i3.10149.

Wadhwa, V., \& Aggarwal, R. (2009). Anatomy of an entrepreneur: Family background and motivation. 24.

Waghid, Z. (2017). Using film and online group blogs to cultivate a community of inquiry: A case studied at a University of Technology in South Africa. Progressio, 38(2), 106-131. https://doi.org/10. 25159/0256-8853/2103.

Waghid, Z., \& Oliver, H. (2017). Cultivating social entrepreneurial capacities in students through film: Implications for social entrepreneurship education. Educational Research for Social Change, 6(2), 76-100. https://doi.org/10.17159/2221-4070/2017/v6i2a6.

Watson, J. (2008). Blended learning: The convergence of online and face-to-face education. North American Council for Online Learning, 572, 16. https://doi.org/10.1016/j.aca.2006.05.012. 
Welsh, D., \& Dragusin, M. (2013). The new generation of massive open online course (MOOCS) and entrepreneurship education. Small Business Institute Journal, 9(1), 51-65.

Williams, D. (2015). The impact of SimVenture on the development of entrepreneurial skills in management students. Industry and Higher Education, 29(5), 379-395. https://doi.org/10.5367/ihe.2015. 0270 .

Wraae, B., Tigerstedt, C., \& Walmsley, A. (2020). Using Reflective videos to enhance entrepreneurial learning. Entrepreneurship Education and Pedagogy. https://doi.org/10.1177/2515127420936955.

Wu, Y., \& Song, D. (2019). Gratifications for social media use in entrepreneurship courses: Learners' perspective. Frontiers in Psychology, 10, 1-12. https://doi.org/10.3389/fpsyg.2019.01270.

Wu, Y.-C. J., Pan, C.-I., \& Yuan, C.-H. (2017). Attitudes towards the use of information and communication technology in management education. Behaviour \& Information Technology, 36(3), 243-254.

Wu, Y. C. J., Wu, T., \& Li, Y. (2019). Impact of using classroom response systems on students' entrepreneurship learning experience. Computers in Human Behavior, 92, 634-645. https://doi.org/10. 1016/j.chb.2017.08.013.

Wu, Y. J., Yuan, C. H., \& Pan, C. I. (2018). Entrepreneurship education: An experimental study with information and communication technology. Sustainability, 10(3), 691. https://doi.org/10.3390/ su10030691.

Zhou, M., \& Xu, H. (2012). A review of entrepreneurship education for college students. Administrative Sciences, 2, 82-98.

Publisher's Note Springer Nature remains neutral with regard to jurisdictional claims in published maps and institutional affiliations.

\section{Authors and Affiliations}

\section{Li Chen ${ }^{1}(1) \cdot$ Dirk Ifenthaler ${ }^{1,2}$. Jane Yin-Kim Yau ${ }^{1}$}

$\triangle$ Li Chen

lcheb@mail.uni-mannheim.de

1 University of Mannheim, L4, 1, 68161 Mannheim, Germany

2 Curtin University, Perth, Australia 